\title{
Gut Microbiota and Atherosclerosis-Focusing on the Plaque Stability
}

\author{
Xinyi Shen ${ }^{1}$, Lihua Li $^{2}$, Zhen Sun ${ }^{1}$, Guangyao Zang ${ }^{1}$, Lili Zhang ${ }^{1}$, Chen Shao ${ }^{1}$ and \\ Zhongqun Wang ${ }^{1 *}$ \\ ${ }^{1}$ Department of Cardiology, Affiliated Hospital of Jiangsu University, Zhenjiang, China, ${ }^{2}$ Department of Pathology, Affiliated \\ Hospital of Jiangsu University, Zhenjiang, China
}

\section{OPEN ACCESS}

Edited by:

Tohru Fukai,

Augusta University, United States

Reviewed by:

Jun-ichiro Koga,

Kyushu University, Japan Christoph Eugen Hagemeyer,

Monash University, Australia

Sudhahar Varadarajan,

Augusta University, United States

*Correspondence:

Zhongqun Wang wangtsmc@126.com

Specialty section:

This article was submitted to

Atherosclerosis and Vascular

Medicine,

a section of the journal

Frontiers in Cardiovascular Medicine

Received: 16 February 2021

Accepted: 30 June 2021

Published: 03 August 2021

Citation:

Shen X, Li L, Sun Z, Zang G, Zhang L, Shao $C$ and Wang $Z$ (2021) Gut Microbiota and

Atherosclerosis-Focusing on the Plaque Stability.

Front. Cardiovasc. Med. 8:668532.

doi: 10.3389/fcvm.2021.668532
Cardiovascular diseases (CVDs) are major causes of mortality and morbidity in the modern society. The rupture of atherosclerotic plaque can induce thrombus formation, which is the main cause of acute cardiovascular events. Recently, many studies have demonstrated that there are some relationships between microbiota and atherosclerosis. In this review, we will focus on the effect of the microbiota and the microbe-derived metabolites, including trimethylamine-N-oxide (TMAO), short-chain fatty acids (SCFAs), and lipopolysaccharide (LPS), on the stability of atherosclerotic plaque. Finally, we will conclude with some therapies based on the microbiota and its metabolites.

Keywords: atherosclerosis, metabolites, therapies, plaque stability, gut microbiota

\section{INTRODUCTION}

Cardiovascular diseases (CVDs) are the most common underlying cause of death accounting for an estimated 17.8 million of 54 million total deaths (1). Atherosclerosis, determined as to be the underlying pathology of CVD, is increasing in prevalence worldwide (2). The traditional risk factors found associated with atherosclerosis include hypertension, hyperlipidemia, diabetes mellitus, obesity, and smoking (3). In recent years, the incidence of atherosclerosis has continued to increase which may indicate that these risk factors cannot fully explain the pathogenesis of atherosclerosis. There is a more urgent need to deepen our understanding of the underlying mechanisms of atherosclerosis.

With the development of technology, our knowledge of the roles of the microbiota in the host has increased drastically. With 16S RNA sequencing and high-throughput sequencing, scientists have found that in the atherosclerotic plaque, bacterial DNA exists (4). Besides, there are several studies proving that the metabolites from microbiota also can influence the development of atherosclerosis. Short-chain fatty acids have already been proven to play protective roles in atherosclerosis, stabilizing plaque $(5,6)$. Simultaneously, they also found that trimethylamine-N-oxide and lipopolysaccharide make the vascular endothelium disorder and plaque unstable and facilitate thrombosis, but the intrinsic mechanism is still not clear $(7,8)$.

In recent years, several studies have investigated the effects of the gut microbiota on atherosclerosis and proved that there are some connections between cardiovascular events and atherosclerotic plaque characteristics (9-19). However, the roles of the gut microbiota in the stability of plaque are still unclear. Therefore, in this review, we will discuss the microbiota changing in the atherosclerosis and whether there is a relationship between the bacterial flora and different conditions of atherosclerosis. Besides, we will state the metabolites from microbiota and how they can impact atherosclerosis. Moreover, we will discuss whether therapeutic strategies that target the intestinal microbiota to alleviate the development of atherosclerosis are possible. 


\section{MICROBIOTA}

\section{Composition and Development of Gut Microbiota}

Gut microbiota is the collection of microorganisms including viruses, archaea, fungi, and bacteria which are the most abundant components in the gut (20). The microbiota usually exists in the gastrointestinal (GI) tract, especially in the ascending colon which is mostly anaerobic and characterized by a nutrient-rich environment that is beneficial for the propagation of microorganisms (21). The infant's gut microbiota, determined by the mode of delivery, appears to be unstable and lacks diversity. The intestines of infants born through the vagina, primarily composed of Lactobacillus and Prevotella, are initially colonized by vaginal microorganisms. However, the infant's gut microbiota, born through cesarean section, is modified and dominated by Streptococcus, Corynebacterium, and Propionibacterium, similar to the skin of human (22). Thus, the infants who were delivered by cesarean section may be more susceptible to pathogen infections. Watson et al. found that $64-82 \%$ of newborns infected with methicillin-resistant Staphylococcus aureus were delivered by cesarean section (23). Influenced by the environment around the infant, the intestinal microbiota evolves until approximately the age of 3 , becoming a diverse, complex, and stable collection, with $6070 \%$ similarity to the adult gut microbiota (24). During development, some ingredients can affect the microbiota such as diet (i.e., breast milk or formula feeding) and the use of antibiotics, which is usually reported to be related to the disruption of the infant gut microbiota. Several experiments found that the infant gut microbiota can benefit long-term health and human gut microbiota in the early stage is related to particular adult health conditions $(21,25-27)$.

The gut microbiota of adults is mainly composed of five phyla: Bacteroidetes, Firmicutes, Actinobacteria, Proteobacteria, and Cerrucomicrobia. The healthy bacterial community Bacteroidetes and Firmicutes together account for over 90\% of the total bacterial species (28). Simultaneously, the Firmicutes/Bacteroidetes ratio ( $\mathrm{F} / \mathrm{B}$ ratio), which is viewed as a health indicator of intestinal microbiota in all individuals, in different people is not the same. The $\mathrm{F} / \mathrm{B}$ ratio increases in people who are obese (the phylum Firmicutes increasing, with the phylum Bacteroidetes decreasing) and is also related to some cardiovascular diseases (29-35). Emoto et al. proved that in coronary artery disease (CAD) patients, there are some changes in microbial composition, with a significant increase in Lactobacillales (Firmicutes) abundance and a decrease in Bacteroidetes abundance (13). Besides, several studies in hypertensive models demonstrated that there is a higher F/B ratio (Figure 1) $(31,36,37)$. The gut microbiota not only develops in the early stage of infant as mentioned above but in elderly individuals also changes within bacterial diversity and shifting of the dominant species (e.g., decreasing abundance of beneficial microorganisms and increasing abundance of facultative anaerobic bacteria). These changes may be related to the development of atherosclerosis in elderly individuals $(38,39)$.

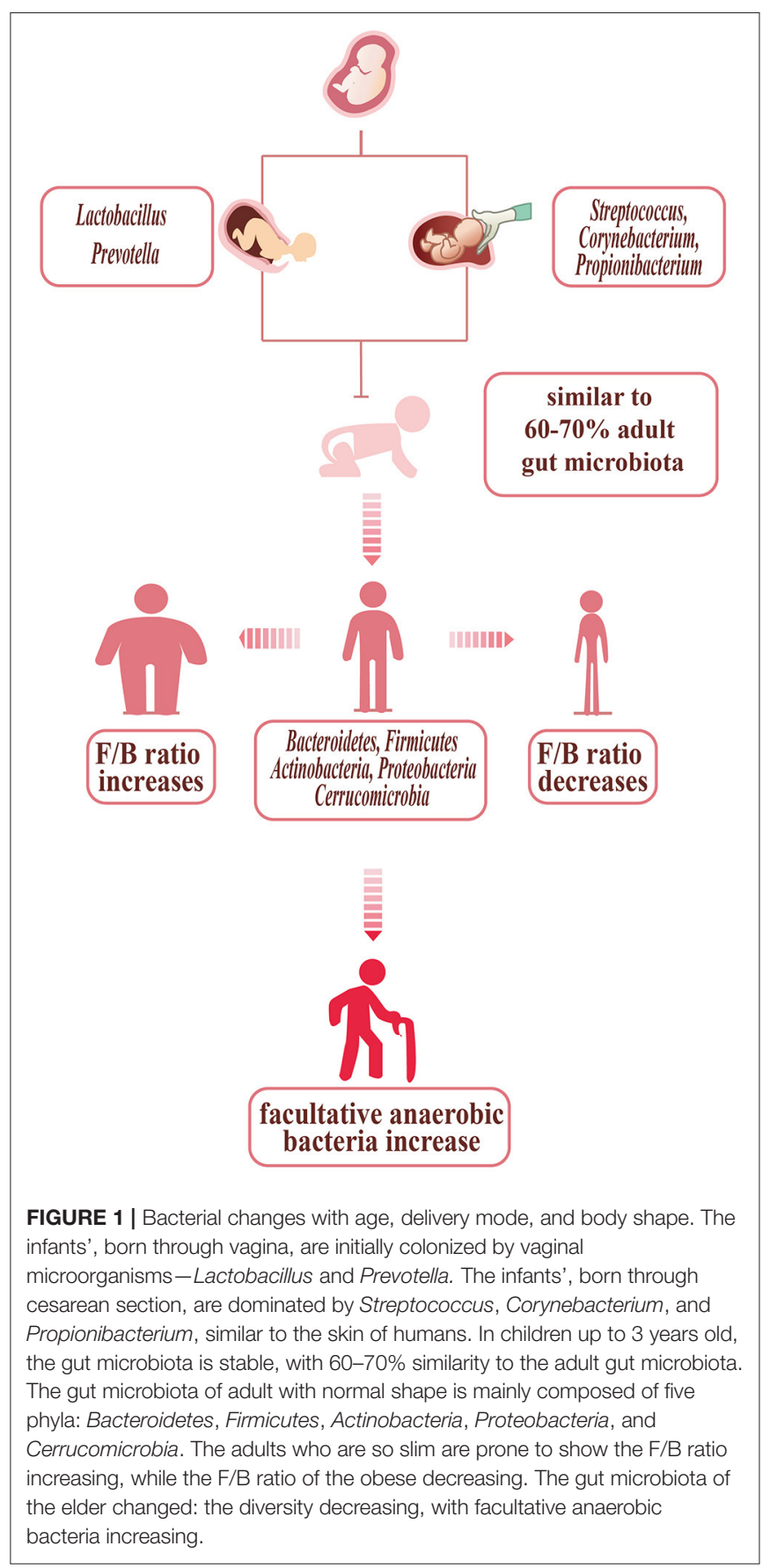

\section{Leaky Gut and Atherosclerosis}

The term "dysbiosis" usually refers to the imbalance of microbial communities, which is related to the changes in either microbial composition or mucosal barrier function disruption. Gut dysbiosis is usually caused by various factors such as high-fat diet, several diseases, and antibiotic overuse (20, 40). Gut microbiota changes can also affect gut permeability, thereby leading gut bacterial DNA translocation, influencing metabolites and endotoxins absorbed into circulation. In the 
healthy condition, there is a multifaceted intestinal barrier system including physical, biochemical, and immunological components. The intestinal epithelial cells (IECs), a single layer of cells, are the main part of the physical intestinal barrier, which are connected by tight junction proteins. In addition, two layers of mucus and gut commensal bacteria also serve as a physical barrier to prevent damaging luminal contents absorbed into circulation (41-43).

Hypertension and atherosclerosis have been proven above to be related to gut microbiota dysbiosis with an increase in the $\mathrm{F} / \mathrm{B}$ ratio via productions of acetate and decreasing of butyrate. Butyrate, once proved to be the main energetic resource of IECs, is able to maintain the stability of gut barrier. High-fat intake thought as the risk factor for atherosclerosis can induce remarkable changes in gut microbiota composition (44-47). Desai et al. conducted an experiment to prove that consumption of low-fiber foods can lead to the expansion of mucus-degrading bacteria, including Akkermansia muciniphila and Bacteroides caccae, which significantly decreases the thickness of the mucus layer in mice, causing higher susceptibility to pathogens and endotoxins. Moreover, intake of a high-fat diet showed that Lactobacillus abundance greatly decreased and Oscillibacter abundance increased, which caused a significant permeability increase in the proximal colon (48). Besides, infections can play a role in regulating the mucosal barrier. Helicobacter pylori directly increasing epithelial permeability by redistributing the TJ protein ZO-1 may, for example, play a role in the atherosclerosis (49-51). Overall, dysbiosis of the gut microbiota induced by a number of factors can lead to leaky gut, causing the translocation of bacteria and some injurious metabolites produced by the gut microbiota and subsequently triggering a series of abnormal immune responses and the development of atherosclerosis.

\section{Microbiota and Atherosclerosis}

In recent years, several studies have confirmed the presence of bacterial DNA in atherosclerotic plaque which may contribute to the development of cardiovascular disease (52). In addition, researchers have also found that compared with people without atherosclerosis, the patients with atherosclerosis (Table 1) showed some differences in the gut microbiota (9-19, 53). Garshick et al. donated aortas of Apoe-/- mice with atherosclerosis into normolipidemic wild-type mice, then feeding antibiotic. They found that compared with Apoe-/- mice, plaque size in $\mathrm{Abx}-\mathrm{WT}$ recipient mice did not differ, but has a $32 \%$ reduction in CD68-expressing cells, suggesting that gut microbiota is a potential role of the microbiome to influence atherosclerosis inflammation (54). As shown in Table 1, two studies found that patients with coronary heart disease (CHD) or high IMT values, a marker of subclinical atherosclerosis, have greater Firmicutes/Bacteroidetes ratio, which are usually found in people who are obese and can confirm the protective effect of butyrate in the CVDs $(15,19)$. Simultaneously, the other two trials indicated that phyla Escherichia are enriched in the patients with subclinical carotid atherosclerosis (SCA) and coronary artery disease $(\mathrm{CAD})$ which provide a new predictor in the development of atherosclerosis $(16,17)$. Ji et al. once found that Acidaminococcus was more abundant in the CAS patient.
Acidaminococcus was once often enriched in patients with several inflammatory diseases and positively correlated with a proinflammatory diet, which may indicate that Acidaminococcus was a proinflammatory microbiota and represent inflammatory status in the development of AS (18). In atherosclerotic plaques, phylum Proteobacteria dominated and the phylum Firmicutes, predominantly found in the gut, is also present in atherosclerotic plaques. However, according to previous studies, there is still no conclusion on whether the microbiota is important in the development of AS or not. Mitra et al. proved that the gut microbiota in patients with stable plaques shows a significant difference from that in patients with unstable plaque. However, Hållenius et al. found that there were no major differences in bacterial DNA content or microbial composition between stable and unstable plaques $(9,11)$. Some researchers have observed that bacterial DNA may trigger macrophages thereby activating the innate immune system via Toll-like receptor 2 (TLR2) and TLR4 which are closely related to the stability of plaques (55-57). The research conducted by Chen et al. proved that the feasibility of remodeling of the gut microbiome to prevent the onset and progression of atherosclerosis in LDLr-/- mice which indicates that the gut microbiota plays some roles in atherosclerosis and may also provide a new therapy (58). One study (6) also found that introducing the proinflammatory Casp1-/- microbiota into Ldlr-/- mice promotes plaque growth with neutrophil accumulation in plaques and a significant reduction in the short-chain fatty acids producing taxonomies (Akkermansia, Christensenellaceae, Clostridium, and Odoribacter). In summary, there is no clear conclusion on whether there exists a crucial gut microbiota for the development of atherosclerosis. Studies should still focus on the items about the relationships of the gut microbiota, bacteria in plaques, and atherosclerosis.

\section{METABOLITE}

\section{TMAO}

\section{TMAO Metabolism}

Trimethylamine N-oxide (TMAO), a proatherogenic metabolite, is generated from phosphatidylcholine, carnitine, $\gamma$-butyrobetaine, betaine, and crotonobetaine, which are mainly from animal-derived foods, such as red meat, eggs, dairy products, and salt-water fish $(59,60)$.

Trimethylamine (TMA) is generated by the enzymes produced by the gut microbiota, which includes three types. The first one is cutC/D, which is abundant in the Desulforibrio, Desulfuricans, Protebacteria (Grammaprotebacteria, Deltaprotebacteria), and Proteus mirabilis Firmicattes (Clostridia, Bacillus) $(61,62)$. Wang et al. have proved that 3,3-dimethyl1-butanol (DMB), a structural analog of choline, can inhibit cutC/D choline TMA lyase activities to decrease the serum TMAO level, which may serve as a potential therapeutic approach for the treatment of cardiometabolic diseases (63). However, Orman et al. have argued that DMB has no use in inhibiting choline-metabolizing enzyme cutC. In addition, a small molecule, betain aldehyde, can effectively inhibit this kind of enzyme. The others are CtnA/B and Yea X/Y, which are proved to be highly homologous $(64,65)$. 
TABLE 1 | Different kinds of bacteria present in the plaque, and the gut bacterial changes between the controls and patients.

\begin{tabular}{|c|c|c|c|c|c|}
\hline & References & Year (species) & Method & Disease & Bacteria \\
\hline \multirow[t]{8}{*}{ Plaque } & Koren et al., (53) & $2010(H)$ & 16SrRNA & AS & Proteobacteria and Firmicutes \\
\hline & & & & & $\begin{array}{l}\text { Three OTUs -Propionibacterineae, one OTU -Burkholderia were } \\
\text { specific for atherosclerotic plaques }\end{array}$ \\
\hline & Mitra et al., (9) & $2015(H)$ & 16S rRNA & Symptomatic AS & $\begin{array}{l}\text { Helicobacteraceae, Neisseriaceae, sulfur-consuming families and } \\
\text { Thiotrichaceae }\end{array}$ \\
\hline & & & & Asymptomatic AS & $\begin{array}{l}\text { Porphyromonadaceae, Bacteroidaceae, Micrococcaceae, and } \\
\text { Streptococcaceae }\end{array}$ \\
\hline & Ziganshina et al., (10) & $2016(H)$ & 16S rRNA & AS & $\begin{array}{l}\text { Proteobacteria (71.4-97.3\%) [Burkholderiales (67.0-94.1\%); } \\
\text { Actinobacteria (0.2-24.1\%) ] }\end{array}$ \\
\hline & & & & & $\begin{array}{l}\text { Bacteroidetes (0.3-2.1\%) [Saprospirales }(0.3-2.1 \%) \text { and Firmicutes } \\
(0.1-5.2 \%)]\end{array}$ \\
\hline & Lindskog Jonsson et al., (11) & $2017(H)$ & 16S rRNA & AS & $\begin{array}{l}\text { Proteobacteria (48.3\%), Actinobacteria (40.2\%), Firmicutes (4.0\%), } \\
\text { Cyanobacteria (3.9\%), Bacteroidete }\end{array}$ \\
\hline & & & & & $\begin{array}{l}\text { No differences in the microbial composition between symptomatic } \\
\text { AS and asymptomatic AS }\end{array}$ \\
\hline \multirow[t]{11}{*}{ Gut } & Koren et al., (53) & $2010(H)$ & 16S rRNA & AS & No significant difference between the AS and controls \\
\hline & Karlsson et al., (12) & $2012(H)$ & Metagenomics & Symptomatic AS & $\begin{array}{l}\text { Collinsella dominating,the Ruminococcus enterotype genes in the } \\
\text { peptidoglycan pathway were enriched }\end{array}$ \\
\hline & & & & control & $\begin{array}{l}\text { Eubacterium and Roseburia and three species of Bacteroides } \\
\text { dominating }\end{array}$ \\
\hline & Emoto et al., (13) & $2016(H)$ & 16S rRNA & CAD & The order Lactobacillales increasing \\
\hline & & & & & Phylum Bacteroidetes (Bacteroides + Prevotella) decreasing \\
\hline & Jie et al., (14) & $2017(H)$ & Metagenomics & ACVD & $\begin{array}{l}\text { Escherichia coli, Klebsiella spp., Enterobacter aerogenes, } \\
\text { Ruminococcus gnavus, Eggerthella lent increasing }\end{array}$ \\
\hline & & & & & $\begin{array}{l}\text { Roseburia intestinalis and Faecalibacterium cf. prausnitzii } \\
\text { (butyrate-producing bacteria) reducing }\end{array}$ \\
\hline & Cui et al., (15) & $2017(H)$ & Metagenomics & $\mathrm{CHD}$ & Phyla Bacteroidetes and Proteobacteria decreasing \\
\hline & & & & & Phyla Firmicutes and Fusobacteria increasing \\
\hline & Zhu et al., (16) & $2018(H)$ & 16S rRNA & CAD & Escherichia-Shigella; Enterococcus enriching \\
\hline & & & & & $\begin{array}{l}\text { Faecalibacterium; Subdoligranulum; Roseburia; Eubacterium } \\
\text { rectale depleting }\end{array}$ \\
\hline
\end{tabular}

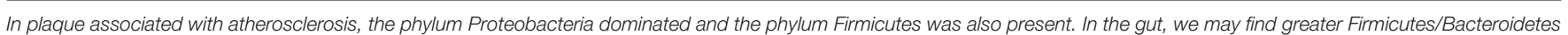
ratio and phyla Escherichia was enriched in patients with atherosclerosis.

TMA formed in the gut is absorbed into the portal circulation and then oxidized to TMAO by the action of hepatic flavin containing monooxygenases FMO3 and FMO1 (66). Some studies have demonstrated that knockdown of the FMO3 gene can significantly reduce the production of TMAO $(67,68)$. In recent years, several new approaches have been found to inhibit the TMAO formation to alleviate the development of atherosclerosis $(69,70)$. However, most researches conducted in vivo studies are in murine models, with few in humans. In that circumstance, reducing TMAO to reduce the incidence of atherosclerosis with some effective, safe strategies may significantly benefit public health.

\section{TMAO and Plaque Stability}

Some studies have indicated that TMAO is an independent predictor of the cardiovascular diseases. In this review, we will discuss the effect of TMAO on the atherosclerotic plaque stability (Figure 2). Senthong et al. and Sheng et al. have discovered that plasma TMAO levels are closely related to the coronary atherosclerotic burden in patients with ST-segment elevation myocardial infarction (STEMI) and stable coronary artery disease (CAD), as quantified by the Synergy Between PCI with Taxus and Cardiac Surgery (SYNTAX) score $(71,72)$. Liu et al. once proved that the non-culprit plaques in CAD patients with higher TMAO levels have exhibited more vulnerable characteristics: thinner fibrous cap thinner (FCT), higher presence of a thin-cap fibroatheroma (TCFA), and microvessels (73). Simultaneously, in one experiment, researchers have discovered that high-choline diet fed on mice intends to increase intraplaque hemorrhage instead of altering atherosclerotic burden or plaque composition, which is a relatively novel finding (74). In recent years, more trials found that TMAO may become a totally new marker to predict future risk of CVDs, which focused on the appropriate serum levels to diagnose CVDs $(75,76)$. It is important to differentiate between plaque rupture and plaque erosion to determine a personalized treatment strategy. In patients with STEMI, the treatment used for plaque rupture and plaque erosion is completely different. Tan et al. have concluded that the cutoff threshold of TMAO was $1.95 \mu \mathrm{M}$ for discriminating plaque rupture from plaque erosion with maximum sensitivity 
and specificity (72). In addition, TML (a precursor of TMAO) and GBB (an intermediate product of L-carnitine) were shown to predict the cardiovascular diseases independently in recent studies $(77,78)$.

\section{Mechanisms}

Mechanisms on how TMAO is able to promote atherosclerosis have already been studied at the molecular level. In the context of immunity, TMAO could activate heat shock protein 60 (HSP60), which has been shown to be the initiating event in the atherosclerosis and to take part in foam cell formation via Tolllike receptors, which can also be activated by SR-A1 and CD36 in macrophages after TMAO stimulation (79-82). Besides, TMAO could induce NLRP3 activation, which promotes IL-18 and IL$1 \beta$ expression to trigger inflammation, which contributed to the endothelial injury that initiates atherosclerosis $(83,84)$. In the inflammation part, TMAO could induce the expression of IL-1, TNF- $\alpha$, C-reactive protein (CRP) via mitogen-activated protein kinase (MAPK), and NF-kappa B (NF-кB) signaling to promote the formation of atherosclerosis (85-88). TMAO also can reduce the reverse cholesterol transport through activating the nuclear receptor Farnesoid X receptor (FXR) and small heterodimer partner (SHP) to inhibit the expression of Cyp7al, which could reduce the synthesis of bile acids in the liver with the result of accelerating atherosclerosis development $(89,90)$.

\section{Lipopolysaccharide}

Lipopolysaccharide (LPS) which is a central component of the outer membrane in Gram-negative bacteria usually exists in the gut and oral cavity has a great impact on the atherosclerosis. LPS existing in the outer membrane of Gram-negative bacteria contains three parts: lipid A, a core oligosaccharide, and the O-antigenic polysaccharide (91-94). LPS can be detected in healthy human's plasma at low concentrations (between 1 and $200 \mathrm{pg} / \mathrm{ml}$ ), which proves that small amounts of LPS are able to cross the intestinal barrier. Although the function of low circulatory levels of LPS is still unclear, some researches have recently shown that it may be related to the immune modulation with some benefits on resisting infection or some damages to increase inflammation (95-97).

However, in some conditions, intestinal permeability can be increased leading the circulatory levels of LPS to rise. In atherosclerosis, the number of butyrate-producing bacteria decreased, causing a reduction of butyrate levels to result in the dysfunctional gut mucosal barrier which may cause more LPS entering into circulating blood. Besides, the high-fat diet can also lead concentrations of LPS to increase through different ways, especially through the increasing gut permeability $(98,99)$. Firstly, it can cause the excessive chylomicron to form, which may increase the local pressure and cause the loosening of junctional complexes between the enterocytes $(100,101)$. The composition of gut microbiota also can be altered due to the highfat diet. The abundance of Gram-negative bacteria (Bacteroides) increases degrading mucus glycoprotein and leading to increased circulatory concentrations of toxins. Meanwhile, the abundance of Gram-positive bacteria usually promotes a stable environment and inhibits the translocation of bacteria and toxins to decrease
$(102,103)$. Besides, the high-fat diet could decrease the activity of intestinal alkaline phosphatase, which may decrease LPS degradation to increase circulating LPS levels (104, 105). Except for the atherosclerosis and high-fat diet, the other risk factors, such as insulin resistance, hypertension, liver diseases, and other neurological diseases, may also cause the intestinal permeability to increase-leading the circulatory levels of LPS to rise (41).

\section{LPS and Plaque Stability}

LPS has already been proven to be involved in infectious diseases such as septic shock for several years. However, in recent years, some researches have demonstrated that there may be some relationships between LPS and atherosclerosis (106-108). Carnevale et al. have found that circulating levels of LPS and zonulin which is a protein that reflects the condition of intestinal permeability are much higher in patients with critical stenosis of carotid artery $(>70 \%)$ than controls without the plaque, revealing that circulatory levels of LPS may be positively correlated with the atherosclerosis. Besides, the authors discovered that in the area of carotid plaque sections positive for LPS and TLR4, macrophages, which are closely related to the formation of atherosclerosis and the stability of the atherosclerotic plaque, were much bigger than macrophages in the area with less reactivity to LPS and TLR4. In that research, they also found that LPS can activate monocyte via TLR4 activation with an intracellular signaling mechanism involving expressions of Nox2 to increase, which is among the most important cellular producer of reactive oxygen species. As a result, this downstream effect can lead to the formation of oxidized LDL, proving that LPS is a molecule that promotes oxidative stress at the site of atherosclerotic plaque (Figure 2), which may lead to the rupture of the plaque (93). Yoshida et al. have detected species with differential abundance between CAD and controls with $16 \mathrm{~S}$ ribosomal RNA gene sequencing, revealing a significantly lower abundance of Bacteroides vulgatus, Bacteroides dorei, and higher LPS concentration in patients with CAD. Atherosclerosis-prone mice fed with $B$. vulgatus and $B$. dorei then showed attenuation of atherosclerotic lesion formation and decrease in gut microbial lipopolysaccharide production. In that circumstance, they discussed that pathogenesis of atherosclerosis alleviation may be due to dampening of systemic innate immune cell activation and Th1-driven inflammation caused by the live Bacteroides treatment-induced reduction in plasma LPS concentration (8). Loffredo et al. have demonstrated that patients with peripheral arterial disease (PAD) have increased systemic LPS concentrations that inversely correlate with the ankle brachial index (ABI) which indicated that LPS can be the promoter of atherosclerotic burden (109). In the animal experiments, Jaw et al. found that the plaques of mice exposed in LPS presented features of vulnerability including hemorrhage and thrombus formation, which can easily induce acute plaque rupture (110).

\section{LPS-Binding Protein}

When LPS enters into the circulatory system, it can initiate various signaling pathways to recruit inflammatory cells into 


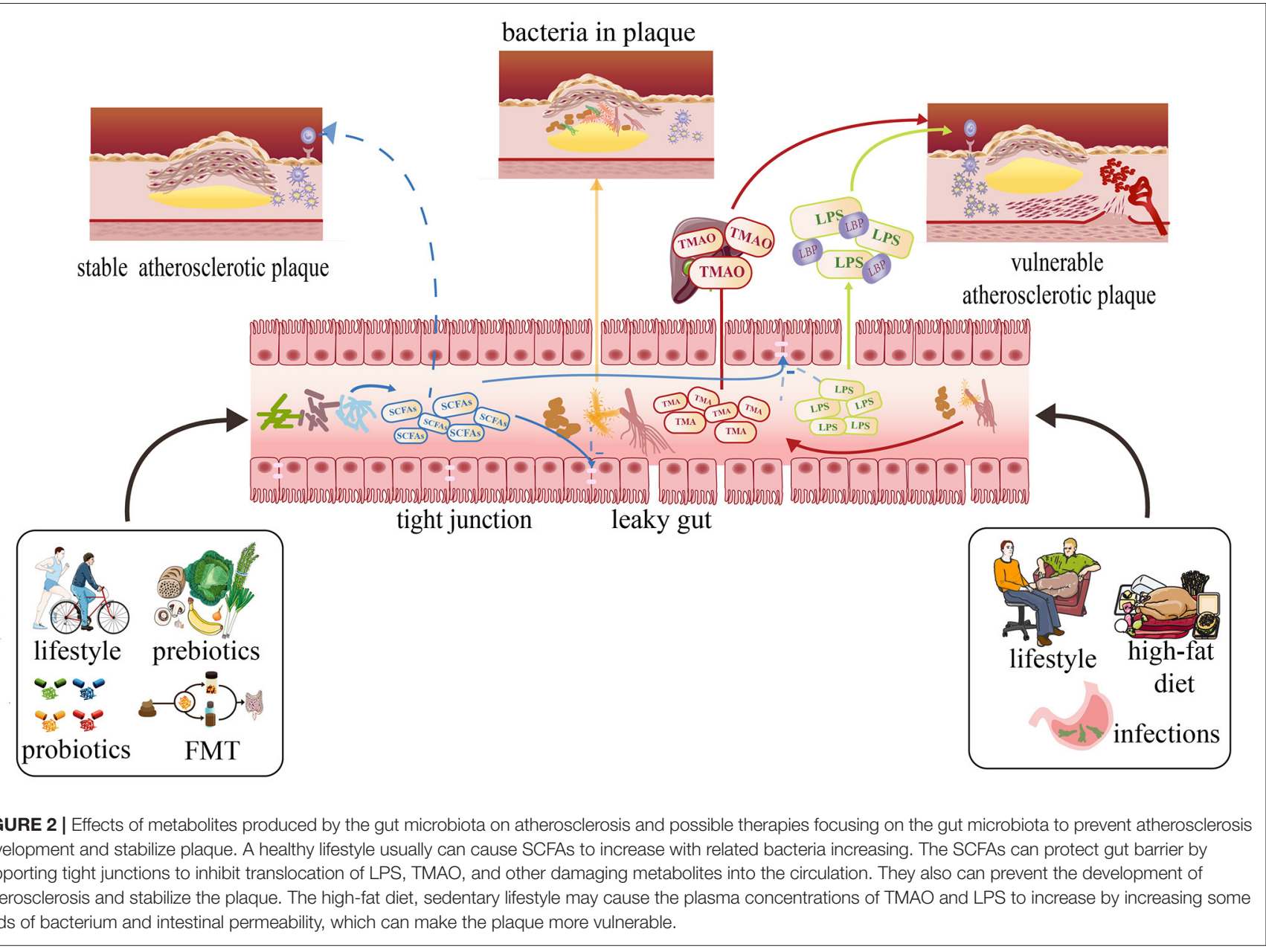

atherosclerotic lesions, which involves a large number of proteins, such as LPS-binding protein (LBP), CD14, Toll-like receptor-4 (TLR4), and MD-2. LBP, a 50-kDa polypeptide mainly synthesized in the liver and released into the bloodstream after glycosylation, is the first protein to bind with LPS, which indicates that it might be a reliable biomarker that predicts the activation of innate immune responses (111-114). Lepper et al. once found that serum LBP levels significantly increased in patients with CAD according to CAD severity compared with those without CAD, which may indicate that LBP might be able to be used as a biomarker for coronary artery disease. They also pointed that LBP deposited in regions of atherosclerosis, indicating it may be involved in the development and progression of atherosclerotic lesions $(115,116)$. Serrano et al. discovered that circulating LBP was positively associated with atherosclerotic risk factors, such as obesity, insulin resistance parameters, and so on. Besides, they also found that circulating LBP may independently contribute to the presence of carotid plaque and the carotid intima-media thickness, which may indicate that LBP is associated with the development of atherosclerotic lesions (117).

\section{Short-Chain Fatty Acids}

Depending on the length of the carbon chain, the fatty acids has been classified into three types, which contains long-chain fatty acids (LCFAs, the number of carbon chain more than 12), midchain fatty acids (MCFAs, the number of carbon chain between 6 and 12), and short-chain fatty acids (SCFAs, the number of carbon chain <6) (118). The short-chain fatty acids are mainly produced from bacterial fermentation of food fiber and the nondigestible carbohydrates containing resistant starch (RS), nonstarch polysaccharides (NSP), oligosaccharides (prebiotics), and so on. The SCFAs were mainly fermented in the large intestine due to its environment (warm, moist, anaerobic, and full of feed residues) which caters for the conditions to make prolific bacterial growth $(119,120)$. SCFAs which are thought as the energy resources are found to play key roles in meditating gut epithelial and immune regulation. As described above, the structure of gut epithelial covered and protected by a mucus layer is essential to prevent the bacteria from spreading into the circular blood, leading susceptibility to enhance infections and the development of chronic inflammatory diseases. In addition, the mucus layer covering and protecting the gut epithelium 
is maintained by the gut microbiota and diet that is mainly due to SCFAs. The main components of SCFAs were acetate, propionate, and butyrate, which account for almost 95\% SCFAs. These SCFAs were mostly produced by some families of bacteria, including anaerobic Bacteroides, Bifidobacterium, Eubacterium, Streptococcus, and Lactobacillus (Table 2). The SCFAs were released at high concentrations in the ascending colon, with a decline in the transverse colon and the descending colon (121, 122).

\section{SCFAs and Atherosclerosis}

Ghosh et al. have proven that attributing to butyrate, whole-milk consumption was inversely associated with CAC progression, which is the independent risk factor for atherosclerosis (123). One experiment once suggested that after ApoE-/mice consumed a diet containing $1 \%$ butyrate for 10 weeks, atherosclerosis in the aorta was reduced by $50 \%$, with lower macrophage infiltration and increased collagen deposition, suggesting a more stable fibrous cap. These phenomena are mostly associated with CD36 decreasing in macrophages and endothelial cells, reduction of proinflammatory cytokines, and lower NFkB activation. They also found that the decrease in macrophage may be due to the reduction of oxidative stress related to NADPH oxidase and iNOS expression levels (124). Vascular smooth muscle cell (VSMC) proliferation is considered to play an important role in the pathogenesis of atherosclerosis (Figure 2). There are several studies proving that butyrate can prevent the development of atherosclerosis by proliferation of VSMCs (125-127). Kasahara et al. put forward a new axis Roseburia-fiber-butyrate with atherosclerotic germ-free ApoE/- mice colonized with a defined community of eight bacteria with or without Roseburia intestinalis. With that axis, the atherosclerotic plaque sizes are reduced by $30 \%$ without affecting the levels of cholesterol and TMAO perhaps relating to the ability of SCFAs to maintain the integrity of the gut $(128,129)$. Besides, Bartolomaeus et al. have found that propionate application to ApoE-/- mice reduced vascular inflammation and atherosclerotic lesion burden and alleviated the level of blood pressure, which is considered traditional risk factors of plaque rupture (130). Overall, the above studies may lead to the development of a new approach-supplementing SCFAs to prevent the development of atherosclerosis and stabilize the plaque in cases of the actual cardiovascular accidents. However, few studies have been conducted in humans, so more explorations of the function of SCFAs are still needed.

\section{Other Metabolites}

There still exist other metabolites produced by gut microbiota affecting the stability of atherosclerosis. Uremic toxins, usually increasing in the chronic kidney disease (CKD), are metabolites of amino acids produced by gut microbiota $(131,132)$. Several studies have proved that the protein-bound uremic toxins can significantly induce VSMC proliferation and VSMC calcification, which are closely related to atherosclerosis (133-135). Besides, phytoestrogens, anthocyanins, and bile acids are also associated with atherosclerosis developing $(136,137)$. Recently, Nemet et al. have found a new metabolite, PAGln, generated by gut microbiota which is connected to cardiovascular disease risk because it increases the possibility of thrombus formation and thrombosis potential (138). Thus, it still has a great potential to explore whether there exist known metabolites or new metabolites connected to the gut bacteria and there being some connections between them and atherosclerosis.

\section{THERAPY}

\section{Daily Lifestyle, Gut Microbiota, and Atherosclerosis \\ Diet}

Diet $(139,140)$ has shown to be closely associated with the composition and diversity of gut microbiota (Figure 2). De Filippo et al. once conducted a study that aimed to find whether there are some differences between the gut microbiota of children (BF) fed with traditional rural African diet, characterized with low in fat and animal protein and rich in starch, fiber, and plant polysaccharide and children (EU) eating a typical western diet high in animal protein, sugar, starch, and fat and low in fiber. AS a result, the Bacteroidetes dominated the gut microbiota of BF children, while the gut microbiota of the EU children was dominated by Firmicutes (141). The F/B ratio above proved to be related to the metabolic situation that is usually found increasing in people who are obese.

WHO has declared that a healthy diet comprises low saturated fats, low salts, and high fruits and vegetables (142). In recent years, scientists have found that adhering to the Mediterranean diet (MeDiet) greatly has been strongly linked to a significant reduction in overall mortality and morbidity, providing a new management approach to prevent cardiometabolic diseases. This diet is featured by high consumption of fruits, vegetables, legumes, unrefined cereals, and nuts; moderate consumption of fish, poultry, and dairy products (principally cheese and yogurt); low consumption of red meat products; use of olive oil as the main edible-fat source; and regular but moderate wine consumption (143-147). Baragetti et al. once found that people without subclinical carotid atherosclerosis consume (SCA) higher amounts of cereals, starchy vegetables, milky products, yogurts, and bakery products compared with those with SCA consuming more mechanically separated meats. The diet whereby people without SCA consume may closely in accord with MeDiet and cause changes in specific bacterial species (demonstrated above) (17). Several studies have noticed that the level of fecal SCFAs proved to play protective roles in the development of AS increased in the patients with MeDiet (148150). Nagpal et al. have detected that MeDiet could make some influence on gut microbiota. Compared with those having the Western diet, macaques fed with the MeDiet presented higher microbial diversity and lower Firmicutes and Verrucomicrobia (lower Firmicutes to Bacteroidetes ratio) (151). One study also found that high adherence to Mediterranean diet was associated with increases in Prevotella and Firmicutes, besides low adherence was correlated with higher urinary TMAO levels (152).

Several researchers have proven that insisting on MeDiet can prevent atherosclerosis development. Some studies focused 
TABLE 2 | Pathways of main SCFA production and their related microorganisms.

\begin{tabular}{|c|c|c|c|c|}
\hline Type & Structures & Pathway & Microorganisms & References \\
\hline \multirow[t]{2}{*}{ Acetate } & & From pyruvate in acetyl-CoA pathway & $\begin{array}{l}\text { Akkermansia muciniphila, Bacteroides spp., Bifidobacterium } \\
\text { spp. } \\
\text { Prevotella spp., Ruminococcus spp. }\end{array}$ & Koh et al., (120) \\
\hline & & Wood-Ljungdahl pathway & $\begin{array}{l}\text { Blautia hydrogenotrophica, Clostridium spp., Streptococcus } \\
\text { spp. }\end{array}$ & \\
\hline \multirow[t]{3}{*}{ Propionate } & & Succinate pathway & $\begin{array}{l}\text { Bacteroides uniformis.;Bacteroides vulgatus.;Prevotella } \\
\text { copri.; } \\
\text { Alistipes putredinis.;Dialister } \\
\text { invisus; Phascolarctobacteriumsuccinatutens; } \\
\text { Akkermansia muciniphila }\end{array}$ & Louis et al., (121) \\
\hline & & Acrylate pathway & Coprococcus catus & \\
\hline & & Propanediol pathway & Roseburia inulinivorans;Eubacterium hallii;Blautia obeum; & \\
\hline \multirow[t]{2}{*}{ Butyrate } & $\mathrm{OH}$ & Butyryl-CoA transferase: acetate Co-A pathway & $\begin{array}{l}\text { Eubacterium rectale; Roseburia inulinivorans; Roseburia } \\
\text { intestinalis; } \\
\text { Eubacterium hallii; Anaerostipes hadrus; Coprococcus catus; } \\
\text { Faecalibacterium prausnitzii;Eubacterium biformec }\end{array}$ & Louis et al., (121) \\
\hline & & Butyrate kinase pathway & Coprococcus eutactus;Subdoligranulum variabile & \\
\hline
\end{tabular}

on the endothelial dysfunction which was the crucial step in AS development (153-155). Besides, adherence to Mediterranean diet also can modulate intima-media thickness and atherosclerotic plaques (156-159). Some scientists have found that MeDiet acted on the atherosclerotic inflammatory process by downregulating proinflammatory biomarkers and upregulating biomarkers associated with the stability of plaque. On the vessel imaging, people intervening with a MedDiet showed a reduction in the height of plaque, suggesting that plaques have been stabilized. In addition, a report indicated that greater adherence to MeDiet may be associated with a decreased burden of carotid atherosclerotic plaque with a reduction in plaque thickness and area. However, the mechanisms that underlie the MeDiet acting on atherosclerosis is still unknown. As we demonstrated before, MeDiet can alter the gut microbiota. Therefore, we hypothesize that the role of MeDiet in AS may have some relationships with gut microbiota.

\section{Prebiotics}

In the past few years, a number of scientists have discovered that intake of appropriate prebiotics may improve health and protect the cardiovascular system (160). The latest concept of prebiotics is "selectively fermented ingredients that allow specific changes, both in the composition and/or activity of the gastrointestinal microbiota that confer benefits upon host wellbeing and health" $(161,162)$. Prebiotics, including the fructans, inulin and oligofructose, resistant starches, and so on, have been found to increase the relative abundance of Bifidobacteria which reflects the situation of gut health to some degree (163-165). Besides, prebiotics were also able to modify blood lipid profiles mainly because of their ability to bind cholesterol or BA in the upper gut and increase sterol excretion, or for some, through their gel-forming nature, which causes a bulking effect in the intestine and triggering satiety (166-168).

\section{Exercise}

It has already been proven by several studies that exercise can alleviate the development of atherosclerosis (169-173). However, whether there are some relationships between the change of gut microbiota induced by sports and atherosclerosis is still not clear (Figure 2). Some investigations have found that changes in microbial diversity caused by exercise are able to improve tissue metabolism, cardiorespiratory fitness, and insulin resistance that can effectively prevent the cardiovascular incidents (174-177). Scientists discovered that compared with sedentary controls, women completing over $3 \mathrm{~h}$ of exercise per week had increased levels of butyrate-producing microbiota, $A$. muciniphila especially associated with a lean body mass index (BMI), and improved metabolism (178).

The modifications of gut microbiota induced by physical exercise are due to the gut transit time, the modification of the bile acids profile, the production of SCFAs via AMPK activation, the modulation of the Toll-like receptor (TLR) signaling pathway, immunoglobulin $\mathrm{A}$, the number of $\mathrm{B}$, and CD4+ T cell (179-182). These factors listed above have already been discovered to be related to the progress of atherosclerosis, providing a new approach to management. Although increasing studies have pointed that physical exercise can make some benefits on modulation of gut microbiota, the intrinsic mechanism should still be explored.

\section{Others}

Except for the lifestyles demonstrated before, there are several new findings about daily intervening factors of gut microbiota in enhancing the stability of plaques. As we all know, $\mathrm{Pu}-$ erh tea displays cholesterol-lowering properties, recent years scientists have some new discoveries on it. Xiao et al. have found that ApoE-/- mice consuming Pu-erh tea can reduce early fatty streak formation and the advanced fibrofatty plaque sizes through alleviating the chronic inflammatory state by reducing NF- $\kappa \mathrm{B}$ activation and promoting macrophage apoptosis 
(183). In addition, Huang et al. have indicated that $\mathrm{Pu}-$ erh tea alters the gut microbiota in mice and humans, predominantly suppressing microbes associated with bile-salt hydrolase (BSH) activity. This finding may present a new kind of therapy on antihypercholesterolemia and antihyperlipidemia with decreasing intestinal BSH microbes or FXR-FGF15 signaling (54). Huang et al. have demonstrated that glycoursodeoxycholic acid (GUDCA) once proven to be able to improve metabolic disorders may protect against atherosclerosis progression by reducing the plaque area and elevating plaque stability. Besides, they also found that the mice gut microbiota dysbiosis fed with GUDCA administration could be partially normalized, suggesting that GUDCA is a potential approach to prevent atherosclerotic cardiovascular diseases (184). Besides, in recent years, people facing more stress and lack of sleep may not only increase inflammation-associated microbial members but also lose species that secrete anti-inflammatory metabolic products. As we described above, such conditions can accelerate the development of atherosclerosis and make plaques more prone to rupture.

\section{Probiotics and Atherosclerosis}

The definition of probiotics is "live strains of strictly selected microorganisms which, when administered in adequate amounts, confer a health benefit on the host (185)." Probiotics can interact with the existing microbial community dynamic through competition with pathogens (Figure 2). Probiotics must satisfy the following criteria: (1) be live microorganisms; (2) can keep alive and stable before use; (3) resistant to the digestion process; (4) be scientifically proven to be beneficial to the host; and (5) be proven to be safe and reliable or a member of the original intestinal microflora. In fact, many products (e.g., yogurt) sold on the market do not cater these basic standards. Up to now, probiotics includes the related bacteria of Lactobacillus, Bifidobacteria, Escherichia coli (E. coli), Enterococcus and some yeasts (186).

Recently, supplementation with adequate probiotics has been shown to beneficially modify a number of major atherosclerosisassociated risk factors, such as hypercholesterolemia, dyslipidemia, hypertension, and chronic inflammation $(187,188)$. However, not all kinds of probiotics have been found to play protective roles in atherosclerosis. Chan et al. have demonstrated that supplementation with VSL\#3, a consortium of eight lyophilized lactic acid bacterial strains, significantly reduced atherosclerosis lesion development of ApoE-/- mice induced by high-fat diet (189). Huang et al. found that the ApoE-/- mice that intervened with L.4356, belonging to Lactobacillus strains, presented a notable reduction in the atherosclerotic lesion area (190). One clinical trial showed that multispecies probiotics supplementation improved several parameters of endothelial dysfunction while Blattl et al. did not find some significant changes in 30 subjects with metabolic syndrome receiving Lactobacillus casei Shirota (191, 192). Several meta-analyses concluded that probiotics were associated with a significant reduction in TC and LDL-C, especially Lactobacillus acidophilus $(193,194)$. Although there is evidence that probiotics played some roles in host lipid profiling, the involved mechanisms are still not fully understood.

Besides, probiotics can improve the integrity of epithelial barriers and function of tight junctions which can effectively inhibit the harmful metabolite (TMAO, LPS, and so on) from entering into the circulatory system, proved to be able to prevent the progress of atherosclerosis (195). In the past, probiotics can make some beneficial effects on atherosclerotic risk factors, providing a promising therapy of atherosclerosis. However, little is understood about the mechanisms underlying the observed effects of probiotics on host health.

\section{Fecal Microbiota Transplantation}

Recently, fecal microbiota transplantation (FMT) is popularized in the treatment of various systemic diseases related to dysbiosis of intestinal microorganisms (Figure 2). Up till now, in refractory and relapsed Clostridium difficile infection (CDI), FMT has already been shown to be effective and a primary therapy (196198). In recent years, some scientists have found that FMT may become a potential approach for treating non-gastrointestinal diseases, such as treating CVDs, metabolic syndrome, diabetes, and so on. Being infused with intestinal microbes from lean donors, the obese patients can enhance insulin sensitivity known as the traditional risk factors for atherosclerosis (199, 200). In some mouse model experiments, FMT have already made some impressive benefits, such as the increasing production of SCFAs, extended lifespan, attenuated myocarditis, and so on $(201,202)$. However, some clinical trials have demonstrated that although FMT can effectively change the composition of gut microbiota, it did not show any practical influence such as TMAO production capacity, parameters related to vascular inflammation, and significant metabolic effects. Besides, the safety of FMT, a new therapeutical approach, is still unclear. First, it can disrupt the existing intestinal microorganisms, regardless of whether the bacteria are beneficial or damaging. Besides, FMT may transfer endotoxins or infectious agents into the circular system causing unnecessary complications $(203,204)$. Thus, more clinical trials and laboratory experiments are needed to study the efficiency of its application and its potential adverse events.

\section{CONCLUSION}

In recent years, gut microbiota have been recognized as another organ of the human body. It not only affects the physiological processes of the host but also has been reported to be associated with several diseases such as cardiovascular diseases, endocrine disease, psychoses, and so on. In these diseases, CVDs were the most common underlying cause of death. In this review, we discussed whether the gut microbiota affects the stability of atherosclerotic plaque, whose rupture may cause a series of malignant events such as acute heart failure, myocardial infarction, and shock. Several studies have found that bacteria exist in atherosclerotic plaque, and there also exist some differences between the stable and unstable plaque. However, there is still no uniform conclusion on whether the bacteria will cause the plaque to more easily rupture or not. Besides, gut microbiota in the patient with atherosclerosis also 
show some changes compared with the control patient without atherosclerosis, and patients in diverse trials also present various alterations of the gut microbiota. Thus, it is still a long way for us to study the relationship between atherosclerosis and microbiota.

Except for the microbiota itself, the metabolites produced by gut microbiota also take various effects on the stability of plaque. As for TMAO, one of the metabolites, a great deal of studies detecting its influences on CVDs showed that it can provide more vulnerable characteristics to plaques. Besides, another metabolite, LPS, involved in infectious diseases has recently shown to have some effects on atherosclerosis based on in experimental and clinical trials by binding to various proteins, such as LBP, CD14, TLR-4, and MD-2. SCFAs, the main energetic resource of IECs, are able to maintain the gut barrier stable which can be the effective management to prevent the other harmful metabolites from entering into the circulation. SCFAs can prevent the development of atherosclerosis through traditional risk factors and VSMC proliferation.

Based on the characteristics of microbiota and its metabolites, there emerges a lot of new treatments to prevent plaque rupture and development of AS. Interference with lifestyle (healthy diet, supplying prebiotics, spending more time on exercise, some

\section{REFERENCES}

1. Virani SS, Alonso A, Benjamin EJ, Bittencourt MS, Callaway CW, Carson AP, et al. Heart disease and stroke statistics-2020 update: a report from the American Heart Association. Circulation. (2020) 141:e139596. doi: 10.1161/CIR.0000000000000757

2. Li JJ, Fang $\mathrm{CH}$. Atheroscleritis is a more rational term for the pathological entity currently known as atherosclerosis. Med Hypotheses. (2004) 63:1002. doi: 10.1016/j.mehy.2004.01.029

3. Komaroff AL. The microbiome and risk for atherosclerosis. JAMA. (2018) 319:2381-2. doi: 10.1001/jama.2018.5240

4. Lehtiniemi J, Karhunen PJ, Goebeler S, Nikkari S, Nikkari ST. Identification of different bacterial DNAs in human coronary arteries. Eur J Clin Invest. (2005) 35:13-6. doi: 10.1111/j.1365-2362.2005.01440.x

5. Chen XF, Chen X, Tang X. Short-chain fatty acid, acylation and cardiovascular diseases. Clin Sci. (2020) 134:65776. doi: 10.1042/CS20200128

6. Brandsma E, Kloosterhuis NJ, Koster M, Dekker DC, Gijbels MJJ, van der Velden S, et al. A proinflammatory gut microbiota increases systemic inflammation and accelerates atherosclerosis. Circ Res. (2019) 124:94100. doi: 10.1161/CIRCRESAHA.118.313234

7. Zhu Y, Li Q, Jiang H. Gut microbiota in atherosclerosis: focus on trimethylamine N-oxide. APMIS. (2020) 128:35366. doi: 10.1111/apm.13038

8. Loffredo L, Ivanov V, Ciobanu N, Deseatnicova E, Gutu E, Mudrea L, et al. Is there an association between atherosclerotic burden, oxidative stress, and gut-derived lipopolysaccharides? Antioxid Redox Signal. (2020) 3:76166. doi: 10.1089/ars.2020.8109

9. Mitra S, Drautz-Moses DI, Alhede M, Maw MT, Liu Y, Purbojati RW, et al. In silico analyses of metagenomes from human atherosclerotic plaque samples. Microbiome. (2015) 3:38. doi: 10.1186/s40168-015-0100-y

10. Ziganshina EE, Sharifullina DM, Lozhkin AP, Khayrullin RN, Ignatyev IM, Ziganshin AM. Bacterial communities associated with atherosclerotic plaques from Russian individuals with atherosclerosis. PLOS ONE. (2016) 11:e0164836. doi: 10.1371/journal.pone.0164836

11. Lindskog Jonsson A, Hållenius FF, Akrami R, Johansson E, Wester P, Arnerlöv C, et al. Bacterial profile in human atherosclerotic plaques. Atherosclerosis. (2017) 263:177-83. doi: 10.1016/j.atherosclerosis.2017.06.016 special drink or food), supplementation with probiotics, and FMT have recently been discussed for application in CVDs. However, due to the lack of long-term clinical trials, safety and effectiveness should still be explored.

\section{AUTHOR CONTRIBUTIONS}

XS conceived the topic and wrote the first draft. LL, ZS, GZ, LZ, $\mathrm{CS}$, and ZW went through the manuscript, tables, and pictures. All authors revised and approved the final draft.

\section{FUNDING}

This work was supported by the following: the National Natural Science Foundation of China (82070455, 81770450); the Open Project Program of Guangxi Key Laboratory of Centre of Diabetic Systems Medicine (GKLCDSM-20210101-02); Research and Innovation Funding Project for College Students in Experimental Animal Center of Jiangsu University; Postgraduate Research and Practice Innovation Program of Jiangsu Province (KYCX20_2881, SJKY19_2585); and Zhenjiang Cardiovascular Clinical Research Center Project (SS2018008).

12. Karlsson FH, Fåk F, Nookaew I, Tremaroli V, Fagerberg B, Petranovic D, et al. Symptomatic atherosclerosis is associated with an altered gut metagenome. Nat Commun. (2012) 3:1245. doi: 10.1038/ncomms2266

13. Emoto T, Yamashita T, Sasaki N, Hirota Y, Hayashi T, So A, et al. Analysis of gut microbiota in coronary artery disease patients: a possible link between gut microbiota and coronary artery disease. J Atheroscler Thromb. (2016) 23:908-21. doi: 10.5551/jat.32672

14. Jie Z, Xia H, Zhong SL, Feng Q, Li S, Liang S, et al. The gut microbiome in atherosclerotic cardiovascular disease. Nat Commun. (2017) 8:845. doi: 10.1038/s41467-017-00900-1

15. Cui L, Zhao T, Hu H, Zhang W, Hua X. Association study of gut flora in coronary heart disease through high-throughput sequencing. Biomed Res Int. (2017) 2017:3796359. doi: 10.1155/2017/3796359

16. Zhu Q, Gao R, Zhang Y, Pan D, Zhu Y, Zhang X, et al. Dysbiosis signatures of gut microbiota in coronary artery disease. Physiol Genomics. (2018) 50:893-903. doi: 10.1152/physiolgenomics.00070.2018

17. Baragetti A, Severgnini M, Olmastroni E, Dioguardi CC, Mattavelli E, Angius A, et al. Gut microbiota functional dysbiosis relates to individual diet in subclinical carotid atherosclerosis. Nutrients. (2021) 13:304. doi: 10.3390/nu13020304

18. Ji L, Chen S, Gu G, Zhou J, Wang W, Ren J, et al. Exploration of crucial mediators for carotid atherosclerosis pathogenesis through integration of microbiome, metabolome, and transcriptome. Front Physiol. (2021) 12:645212. doi: 10.3389/fphys.2021.645212

19. Szabo H, Hernyes A, Piroska M, Ligeti B, Fussy P, Zoldi L, et al. Association between gut microbial diversity and carotid intima-media thickness. Medicina. (2021) 57:195. doi: 10.3390/medicina57030195

20. Bäckhed F, Fraser CM, Ringel Y, Sanders ME, Sartor RB, Sherman PM, et al. Defining a healthy human gut microbiome: current concepts, future directions, and clinical applications. Cell Host Microbe. (2012) 12:61122. doi: 10.1016/j.chom.2012.10.012

21. Jandhyala SM, Talukdar R, Subramanyam C, Vuyyuru H, Sasikala M, Nageshwar Reddy D. Role of the normal gut microbiota. World $J$ Gastroenterol. (2015) 21:8787-803. doi: 10.3748/wjg.v21.i29.8787

22. Dominguez-Bello MG, Costello EK, Contreras M, Magris M, Hidalgo G, Fierer $\mathrm{N}$, et al. Delivery mode shapes the acquisition and structure of the initial microbiota across multiple body habitats in newborns. Proc Natl Acad Sci USA. (2010) 107:11971-5. doi: 10.1073/pnas.1002601107 
23. James L, Gorwitz RJ, Jones RC, Watson JT, Hageman JC, Jernigan DB, et al. Methicillin-resistant Staphylococcus aureus infections among healthy full-term newborns. Arch Dis Child Fetal Neonatal Ed. (2008) 93:F404. doi: 10.1136/adc.2006.104026

24. Kashtanova DA, Popenko AS, Tkacheva ON, Tyakht AB, Alexeev DG, Boytsov SA. Association between the gut microbiota and diet: fetal life, early childhood, and further life. Nutrition. (2016) 32:6207. doi: 10.1016/j.nut.2015.12.037

25. Kim H, Sitarik AR, Woodcroft K, Johnson CC, Zoratti E. Birth mode, breastfeeding, pet exposure, and antibiotic use: associations with the gut microbiome and sensitization in children. Curr Allergy Asthma Rep. (2019) 19:22. doi: 10.1007/s11882-019-0851-9

26. Milani C, Duranti S, Bottacini F, Casey E, Turroni F, Mahony J, et al. The first microbial colonizers of the human gut: composition, activities, and health implications of the infant gut microbiota. Microbiol Mol Biol Rev. (2017) 81:e00036-17. doi: 10.1128/MMBR.00036-17

27. Butel MJ, Waligora-Dupriet AJ, Wydau-Dematteis S. The developing gut microbiota and its consequences for health. J Dev Orig Health Dis. (2018) 9:590-7. doi: 10.1017/S2040174418000119

28. Qin J, Li R, Raes J, Arumugam M, Burgdorf KS, Manichanh C, et al. A human gut microbial gene catalogue established by metagenomic sequencing. Nature. (2010) 464:59-65. doi: 10.1038/nature08821

29. Crovesy L, Masterson D, Rosado EL. Profile of the gut microbiota of adults with obesity: a systematic review. Eur J Clin Nutr. (2020) 74:125162. doi: 10.1038/s41430-020-0607-6

30. Magne F, Gotteland M, Gauthier L, Zazueta A, Pesoa S, Navarrete P, et al. The Firmicutes/Bacteroidetes ratio: a relevant marker of gut dysbiosis in obese patients? Nutrients. (2020) 12:1474. doi: 10.3390/nu12051474

31. Yang T, Santisteban MM, Rodriguez V, Li E, Ahmari N, Carvajal JM, et al. Gut dysbiosis is linked to hypertension. Hypertension. (2015) 65:133140. doi: 10.1161/HYPERTENSIONAHA.115.05315

32. Lyu M, Wang YF, Fan GW, Wang XY, Xu SY, Zhu Y. Balancing herbal medicine and functional food for prevention and treatment of cardiometabolic diseases through modulating gut microbiota. Front Microbiol. (2017) 8:2146. doi: 10.3389/fmicb.2017.02146

33. Cox AJ, West NP, Cripps AW. Obesity, inflammation, and the gut microbiota. Lancet Diabetes Endocrinol. (2015) 3:20715. doi: 10.1016/S2213-8587(14)70134-2

34. Mariat D, Firmesse O, Levenez F, Guimarăes V, Sokol H, Doré J, et al. The Firmicutes/Bacteroidetes ratio of the human microbiota changes with age. BMC Microbiol. (2009) 9:123. doi: 10.1186/1471-2180-9-123

35. Duncan SH, Lobley GE, Holtrop G, Ince J, Johnstone AM, Louis P, et al. Human colonic microbiota associated with diet, obesity and weight loss. Int J Obes. (2008) 32:1720-4. doi: 10.1038/ijo.2008.155

36. Robles-Vera I, Toral M, Romero M, Jiménez R, Sánchez M, Pérez-Vizcaíno F, et al. Antihypertensive effects of probiotics. Curr Hypertens Rep. (2017) 19:26. doi: 10.1007/s11906-017-0723-4

37. Robles-Vera I, Toral M, de la Visitación N, Sánchez M, Gómez-Guzmán M, Muñoz R, et al. Changes to the gut microbiota induced by losartan contributes to its antihypertensive effects. Br J Pharmacol. (2020) 177:200623. doi: 10.1111/bph.14965

38. Salazar N, Arboleya S, Fernández-Navarro T, de Los Reyes-Gavilán CG, Gonzalez S, Gueimonde M. Age-associated changes in gut microbiota and dietary components related with the immune system in adulthood and old age: a cross-sectional study. Nutrients. (2019) 11:1765. doi: $10.3390 /$ nu11081765

39. Salazar N, Valdés-Varela L, González S, Gueimonde M, de Los Reyes-Gavilán CG. Nutrition and the gut microbiome in the elderly. Gut Microbes. (2017) 8:82-97. doi: 10.1080/19490976.2016.1256525

40. Robles Alonso V, Guarner F. Linking the gut microbiota to human health. $\mathrm{Br}$ J Nutr. (2013) 109(Suppl 2):S21-6. doi: 10.1017/S0007114512005235

41. Camilleri M. Leaky gut: mechanisms, measurement and clinical implications in humans. Gut. (2019) 68:1516-26. doi: 10.1136/gutjnl-2019-318427

42. $\mathrm{Mu}$ Q, Kirby J, Reilly CM, Luo XM. Leaky gut as a danger signal for autoimmune diseases. Front Immunol. (2017) 8:598. doi: 10.3389/fimmu.2017.00598

43. Quigley EM. Leaky gut-concept or clinical entity? Curr Opin Gastroenterol. (2016) 32:74-9. doi: 10.1097/MOG.0000000000000243
44. Paone P, Cani PD. Mucus barrier, mucins and gut microbiota: the expected slimy partners? Gut. (2020) 69:2232-43. doi: 10.1136/gutjnl-2020-322260

45. Johansson ME, Ambort D, Pelaseyed T, Schütte A, Gustafsson JK, Ermund A, et al. Composition and functional role of the mucus layers in the intestine. Cell Mol Life Sci. (2011) 68:3635-41. doi: 10.1007/s00018-011-0822-3

46. Van den Abbeele P, Belzer C, Goossens M, Kleerebezem M, Van de Wiele T. Butyrate-producing Clostridium cluster XIVa species specifically colonize mucins in an in vitro gut model. ISME J. (2013) 7:94961. doi: 10.1038/ismej.2012.158

47. Birchenough G, Schroeder BO, Bäckhed F, Hansson GC. Dietary destabilisation of the balance between the microbiota and the colonic mucus barrier. Gut Microbes. (2019) 10:24650. doi: 10.1080/19490976.2018.1513765

48. Desai MS, Seekatz AM, Koropatkin NM, Kamada N, Hickey CA, Wolter $\mathrm{M}$, et al. A dietary fiber-deprived gut microbiota degrades the colonic mucus barrier and enhances pathogen susceptibility. Cell. (2016) 167:133953.e21. doi: 10.1016/j.cell.2016.10.043

49. Yang YJ, Sheu BS. Metabolic interaction of Helicobacter pylori infection and gut microbiota. Microorganisms. (2016) 4:15. doi: $10.3390 /$ microorganisms 4010015

50. Ng GZ, Menheniott TR, Every AL, Stent A, Judd LM, Chionh YT, et al. The MUC1 mucin protects against Helicobacter pylori pathogenesis in mice by regulation of the NLRP3 inflammasome. Gut. (2016) 65:108799. doi: 10.1136/gutjnl-2014-307175

51. Boccellato F, Woelffling S, Imai-Matsushima A, Sanchez G, Goosmann C, Schmid M, et al. Polarised epithelial monolayers of the gastric mucosa reveal insights into mucosal homeostasis and defence against infection. Gut. (2019) 68:400-13. doi: 10.1136/gutjnl-2017-314540

52. Ott SJ, El Mokhtari NE, Musfeldt M, Hellmig S, Freitag S, Rehman A, et al. Detection of diverse bacterial signatures in atherosclerotic lesions of patients with coronary heart disease. Circulation. (2006) 113:92937. doi: 10.1161/CIRCULATIONAHA.105.579979

53. Koren O, Spor A, Felin J, Fåk F, Stombaugh J, Tremaroli V, et al. Human oral, gut, and plaque microbiota in patients with atherosclerosis. Proc Natl Acad Sci USA. (2011) 108(Suppl 1):4592-8. doi: 10.1073/pnas.1011383107

54. Garshick MS, Nikain C, Tawil M, Pena S, Barrett TJ, Wu $\mathrm{BG}$, et al. Reshaping of the gastrointestinal microbiome alters atherosclerotic plaque inflammation resolution in mice. Sci Rep. (2021) 11:8966. doi: 10.1038/s41598-021-88479-y

55. van den Munckhof ICL, Kurilshikov A, Ter Horst R, Riksen NP, Joosten LAB, Rutten JHW. Role of gut microbiota in chronic lowgrade inflammation as potential driver for atherosclerotic cardiovascular disease: a systematic review of human studies. Obes Rev. (2018) 19:171934. doi: 10.1111/obr. 12750

56. Fukuda D, Nishimoto S, Aini K, Tanaka A, Nishiguchi T, KimKaneyama JR, et al. Toll-like receptor 9 plays a pivotal role in angiotensin ii-induced atherosclerosis. J Am Heart Assoc. (2019) 8:e010860. doi: 10.1161/JAHA.118.010860

57. Edfeldt K, Swedenborg J, Hansson GK, Yan ZQ. Expression of toll-like receptors in human atherosclerotic lesions: a possible pathway for plaque activation. Circulation. (2002) 105:1158-61. doi: 10.1161/circ.105.10.1158

58. Chen PB, Black AS, Sobel AL, Zhao Y, Mukherjee P, Molparia B, et al. Directed remodeling of the mouse gut microbiome inhibits the development of atherosclerosis. Nat Biotechnol. (2020) 38:128897. doi: 10.1038/s41587-020-0549-5

59. Miller CA, Corbin KD, da Costa KA, Zhang S, Zeisel SH. Effect of egg ingestion on trimethylamine-N-oxide production in humans: a randomized, controlled, dose-response study. Am J Clin Nutr. (2014) 100:778-86. doi: 10.3945/ajcn.114.08 7692

60. Koeth RA, Levison BS, Culley MK, Buffa JA, Wang Z, Gregory $\mathrm{JC}$, et al. $\gamma$-Butyrobetaine is a proatherogenic intermediate in gut microbial metabolism of L-carnitine to TMAO. Cell Metab. (2014) 20:799812. doi: 10.1016/j.cmet.2014.10.006

61. Craciun S, Balskus EP. Microbial conversion of choline to trimethylamine requires a glycyl radical enzyme. Proc Natl Acad Sci USA. (2012) 109:21307-12. doi: 10.1073/pnas.12156 89109 
62. Rath S, Heidrich B, Pieper DH, Vital M. Uncovering the trimethylamineproducing bacteria of the human gut microbiota. Microbiome. (2017) 5:54. doi: 10.1186/s40168-017-0271-9

63. Wang Z, Roberts AB, Buffa JA, Levison BS, Zhu W, Org E, et al. Non-lethal inhibition of gut microbial trimethylamine production for the treatment of atherosclerosis. Cell. (2015) 163:1585-95. doi: 10.1016/j.cell.2015.11.055

64. Orman M, Bodea S, Funk MA, Campo AM, Bollenbach M, Drennan CL, et al. Structure-guided identification of a small molecule that inhibits anaerobic choline metabolism by human gut bacteria. J Am Chem Soc. (2019) 141:337. doi: 10.1021/jacs.8b04883

65. Martínez-del Campo A, Bodea S, Hamer HA, Marks JA, Haiser HJ, Turnbaugh PJ, et al. Characterization and detection of a widely distributed gene cluster that predicts anaerobic choline utilization by human gut bacteria. mBio. (2015) 6:e00042-15. doi: 10.1128/mBio.00042-15

66. Bennett BJ, de Aguiar Vallim TQ, Wang Z, Shih DM, Meng Y, Gregory J, et al. Trimethylamine-N-oxide, a metabolite associated with atherosclerosis, exhibits complex genetic and dietary regulation. Cell Metab. (2013) 17:4960. doi: 10.1016/j.cmet.2012.12.011

67. Schugar RC, Brown JM. Emerging roles of flavin monooxygenase 3 in cholesterol metabolism and atherosclerosis. Curr Opin Lipidol. (2015) 26:426-31. doi: 10.1097/MOL.0000000000000215

68. Miao J, Ling AV, Manthena PV, Gearing ME, Graham MJ, Crooke $\mathrm{RM}$, et al. Flavin-containing monooxygenase 3 as a potential player in diabetes-associated atherosclerosis. Nat Commun. (2015) 6:6498. doi: 10.1038/ncomms7498

69. Iglesias-Carres L, Hughes MD, Steele CN, Ponder MA, Davy KP, Neilson AP. Use of dietary phytochemicals for inhibition of trimethylamine N-oxide formation. J Nutr Biochem. (2021) 91:108600. doi: 10.1016/j.jnutbio.2021.108600

70. Li X, Su C, Jiang Z, Yang Y, Zhang Y, Yang M, et al. Berberine attenuates choline-induced atherosclerosis by inhibiting trimethylamine and trimethylamine-N-oxide production via manipulating the gut microbiome. NPJ Biofilms Microbiomes. (2021) 7:36. doi: 10.1038/s41522-021-00205-8

71. Senthong V, Wang Z, Li XS, Fan Y, Wu Y, Tang WH, et al. Intestinal microbiota-generated metabolite trimethylamine- $\mathrm{N}$-oxide and 5year mortality risk in stable coronary artery disease: the contributory role of intestinal microbiota in a COURAGE-like patient cohort. J Am Heart Assoc. (2016) 5:e002816. doi: 10.1161/JAHA.115.002816

72. Tan Y, Sheng Z, Zhou P, Liu C, Zhao H, Song L, et al. Plasma trimethylamine $\mathrm{N}$-oxide as a novel biomarker for plaque rupture in patients with STsegment-elevation myocardial infarction. Circ Cardiovasc Interv. (2019) 12:e007281. doi: 10.1161/CIRCINTERVENTIONS.118.007281

73. Liu X, Xie Z, Sun M, Wang X, Li J, Cui J, et al. Plasma trimethylamine Noxide is associated with vulnerable plaque characteristics in CAD patients as assessed by optical coherence tomography. Int J Cardiol. (2018) 265:1823. doi: 10.1016/j.ijcard.2018.04.126

74. Lindskog Jonsson A, Caesar R, Akrami R, Reinhardt C, Fåk Hållenius F, Borén J, et al. Impact of gut microbiota and diet on the development of atherosclerosis in Apoe-/-mice. Arterioscler Thromb Vasc Biol. (2018) 38:2318-26. doi: 10.1161/ATVBAHA.118.311233

75. Tang WHW, Li XS, Wu Y, Wang Z, Khaw KT, Wareham NJ, et al. Plasma trimethylamine $\mathrm{N}$-oxide (TMAO) levels predict future risk of coronary artery disease in apparently healthy individuals in the EPIC-Norfolk prospective population study. Am Heart J. (2021) 236:806. doi: 10.1016/j.ahj.2021.01.020

76. Zheng L, Zheng J, Xie Y, Li Z, Guo X, Sun G, et al. Serum gut microbe-dependent trimethylamine $\mathrm{N}$-oxide improves the prediction of future cardiovascular disease in a community-based general population. Atherosclerosis. (2019) 280:126-31. doi: 10.1016/j.atherosclerosis.2018.11.010

77. Li XS, Wang Z, Cajka T, Buffa JA, Nemet I, Hurd AG, et al. Untargeted metabolomics identifies trimethyllysine, a TMAOproducing nutrient precursor, as a predictor of incident cardiovascular disease risk. JCI Insight. (2018) 3:e99096. doi: 10.1172/jci.insight.9 9096

78. Li XS, Obeid S, Wang Z, Hazen BJ, Li L, Wu Y, et al. Trimethyllysine, a trimethylamine $\mathrm{N}$-oxide precursor, provides near-and long-term prognostic value in patients presenting with acute coronary syndromes. Eur Heart J. (2019) 40:2700-9. doi: 10.1093/eurheartj/ehz259
79. Wick G, Knoflach M, Xu Q. Autoimmune and inflammatory mechanisms in atherosclerosis. Annu Rev Immunol. (2004) 22:361-403. doi: 10.1146/annurev.immunol.22.012703.104644

80. Wick G, Jakic B, Buszko M, Wick MC, Grundtman C. The role of heat shock proteins in atherosclerosis. Nat Rev Cardiol. (2014) 11:51629. doi: 10.1038/nrcardio.2014.91

81. Collot-Teixeira S, Martin J, McDermott-Roe C, Poston R, McGregor JL. CD36 and macrophages in atherosclerosis. Cardiovasc Res. (2007) 75:46877. doi: 10.1016/j.cardiores.2007.03.010

82. Febbraio M, Podrez EA, Smith JD, Hajjar DP, Hazen SL, Hoff HF, et al. Targeted disruption of the class B scavenger receptor CD36 protects against atherosclerotic lesion development in mice. J Clin Invest. (2000) 105:104956. doi: 10.1172/JCI9259

83. Duewell P, Kono H, Rayner KJ, Sirois CM, Vladimer G, Bauernfeind FG, et al. NLRP3 inflammasomes are required for atherogenesis and activated by cholesterol crystals. Nature. (2010) 464:1357-61. doi: 10.1038/nature08938

84. Takahashi M. NLRP3 inflammasome as a novel player in myocardial infarction. Int Heart J. (2014) 55:101-5. doi: 10.1536/ihj.13-388

85. Baker RG, Hayden MS, Ghosh S. NF-кB, inflammation, and metabolic disease. Cell Metab. (2011) 13:11-22. doi: 10.1016/j.cmet.2010.12.008

86. Seldin MM, Meng Y, Qi H, Zhu W, Wang Z, Hazen SL, et al. Trimethylamine $\mathrm{N}$-oxide promotes vascular inflammation through signaling of mitogenactivated protein kinase and nuclear Factor- $\kappa$ B. J Am Heart Assoc. (2016) 5:e002767. doi: 10.1161/JAHA.115.002767

87. Chen ML, Zhu XH, Ran L, Lang HD, Yi L, Mi MT. Trimethylamine-N-oxide induces vascular inflammation by activating the NLRP3 inflammasome through the SIRT3-SOD2-mtROS signaling pathway. J Am Heart Assoc. (2017) 6:e006347. doi: 10.1161/JAHA.117.006347

88. Chou RH, Chen CY, Chen IC, Huang HL, Lu YW, Kuo CS, et al. Trimethylamine $\mathrm{N}$-oxide, circulating endothelial progenitor cells, and endothelial function in patients with stable angina. Sci Rep. (2019) 9:4249. doi: 10.1038/s41598-019-40638-y

89. Ding L, Chang M, Guo Y, Zhang L, Xue C, Yanagita T, et al. Trimethylamine-N-oxide (TMAO)-induced atherosclerosis is associated with bile acid metabolism. Lipids Health Dis. (2018) 17:286. doi: 10.1186/s12944-018-0939-6

90. Yang S, Li X, Yang F, Zhao R, Pan X, Liang J, et al. Gut microbiota-dependent marker TMAO in promoting cardiovascular disease: inflammation mechanism, clinical prognostic, and potential as a therapeutic target. Front Pharmacol. (2019) 10:1360. doi: 10.3389/fphar.2019.01360

91. Whitfield C, Trent MS. Biosynthesis and export of bacterial lipopolysaccharides. Annu Rev Biochem. (2014) 83:99128. doi: 10.1146/annurev-biochem-060713-035600

92. Hettne KM, Weeber M, Laine ML, ten Cate H, Boyer S, Kors JA, et al. Automatic mining of the literature to generate new hypotheses for the possible link between periodontitis and atherosclerosis: lipopolysaccharide as a case study. J Clin Periodontol. (2007) 34:1016-24. doi: 10.1111/j.1600-051X.2007.01152.x

93. Yoshida N, Emoto T, Yamashita T, Watanabe H, Hayashi T, Tabata T, et al. Bacteroides vulgatus and Bacteroides dorei reduce gut microbial lipopolysaccharide production and inhibit atherosclerosis. Circulation. (2018) 138:2486-98. doi: 10.1161/CIRCULATIONAHA.118.033714

94. Maldonado RF, Sá-Correia I, Valvano MA. Lipopolysaccharide modification in Gram-negative bacteria during chronic infection. FEMS Microbiol Rev. (2016) 40:480-93. doi: 10.1093/femsre/fuw007

95. Henderson JC, Herrera CM, Trent MS. AlmG, responsible for polymyxin resistance in pandemic Vibrio cholerae, is a glycyltransferase distantly related to lipid A late acyltransferases. J Biol Chem. (2017) 292:2120515. doi: 10.1074/jbc.RA117.000131

96. Williams TM, Leeth RA, Rothschild DE, McDaniel DK, Coutermarsh-Ott SL, Simmons AE, et al. Caspase-11 attenuates gastrointestinal inflammation and experimental colitis pathogenesis. Am J Physiol Gastrointest Liver Physiol. (2015) 308:G139-50. doi: 10.1152/ajpgi.00234.2014

97. Ji Y, Sakata Y, Tso P. Nutrient-induced inflammation in the intestine. Curr Opin Clin Nutr Metab Care. (2011) 14:31521. doi: 10.1097/MCO.0b013e3283476e74

98. Moreira AP, Texeira TF, Ferreira AB, Peluzio Mdo C, Alfenas Rde C. Influence of a high-fat diet on gut microbiota, intestinal 
permeability and metabolic endotoxaemia. $\mathrm{Br} \quad J \quad$ Nutr. (2012) 108:801-9. doi: 10.1017/S0007114512001213

99. Sturm A, Dignass AU. Epithelial restitution and wound healing in inflammatory bowel disease. World J Gastroenterol. (2008) 14:34853. doi: $10.3748 /$ wjg. 14.348

100. Cani PD, Possemiers S, Van de Wiele T, Guiot Y, Everard A, Rottier O, et al. Changes in gut microbiota control inflammation in obese mice through a mechanism involving GLP-2-driven improvement of gut permeability. Gut. (2009) 58:1091-103. doi: 10.1136/gut.2008.165886

101. Wang Z, Xiao G, Yao Y, Guo S, Lu K, Sheng Z. The role of bifidobacteria in gut barrier function after thermal injury in rats. J Trauma. (2006) 61:6507. doi: 10.1097/01.ta.0000196574.70614.27

102. Ruseler-van Embden JG, van Lieshout LM, Gosselink MJ, Marteau P. Inability of Lactobacillus casei strain GG, L. acidophilus and Bifidobacterium bifidum to degrade intestinal mucus glycoproteins. Scand J Gastroenterol. (1995) 30:675-80. doi: 10.3109/00365529509096312

103. Lynes MD, Widmaier EP. Involvement of CD36 and intestinal alkaline phosphatases in fatty acid transport in enterocytes, and the response to a high-fat diet. Life Sci. (2011) 88:384-91. doi: 10.1016/j.lfs.2010.12.015

104. Lynes M, Narisawa S, Millán JL, Widmaier EP. Interactions between CD36 and global intestinal alkaline phosphatase in mouse small intestine and effects of high-fat diet. Am J Physiol Regul Integr Comp Physiol. (2011) 301:R1738-47. doi: 10.1152/ajpregu.00235.2011

105. Funk JL, Feingold KR, Moser AH, Grunfeld C. Lipopolysaccharide stimulation of RAW 264.7 macrophages induces lipid accumulation and foam cell formation. Atherosclerosis. (1993) 98:67-82. doi: 10.1016/0021-9150(93)90224-I

106. Sieve I, Ricke-Hoch M, Kasten M, Battmer K, Stapel B, Falk CS, et al. A positive feedback loop between IL-1 $\beta$, LPS and NEU1 may promote atherosclerosis by enhancing a pro-inflammatory state in monocytes and macrophages. Vascul Pharmacol. (2018) 103-5:16-28. doi: 10.1016/j.vph.2018.01.005

107. Lehr HA, Sagban TA, Ihling C, Zähringer U, Hungerer KD, Blumrich $\mathrm{M}$, et al. Immunopathogenesis of atherosclerosis: endotoxin accelerates atherosclerosis in rabbits on hypercholesterolemic diet. Circulation. (2001) 104:914-20. doi: 10.1161/hc3401.093153

108. Carnevale R, Nocella C, Petrozza V, Cammisotto V, Pacini L, Sorrentino V, et al. Localization of lipopolysaccharide from Escherichia coli into human atherosclerotic plaque. Sci Rep. (2018) 8:3598. doi: 10.1038/s41598-018-22076-4

109. Jaw JE, Tsuruta M, Oh Y, Schipilow J, Hirano Y, Ngan DA, et al. Lung exposure to lipopolysaccharide causes atherosclerotic plaque destabilisation. Eur Respir J. (2016) 48:205-15. doi: 10.1183/13993003.00972-2015

110. Triantafilou M, Triantafilou K. Lipopolysaccharide recognition: CD14, TLRs and the LPS-activation cluster. Trends Immunol. (2002) 23:3014. doi: 10.1016/S1471-4906(02)02233-0

111. Lee JD, Kato K, Tobias PS, Kirkland TN, Ulevitch RJ. Transfection of CD14 into 70Z/3 cells dramatically enhances the sensitivity to complexes of lipopolysaccharide (LPS) and LPS binding protein. J Exp Med. (1992) 175:1697-705. doi: 10.1084/jem.175.6.1697

112. Han J, Mathison JC, Ulevitch RJ, Tobias PS. Lipopolysaccharide (LPS) binding protein, truncated at Ile-197, binds LPS but does not transfer LPS to CD14. J Biol Chem. (1994) 269:8172-5. doi: 10.1016/S0021-9258(17)37176-4

113. Tobias PS, Soldau K, Kline L, Lee JD, Kato K, Martin TP, et al. Crosslinking of lipopolysaccharide (LPS) to CD14 on THP-1 cells mediated by LPS-binding protein. J Immunol. (1993) 150:3011-21.

114. Lepper PM, Kleber ME, Grammer TB, Hoffmann K, Dietz S, Winkelmann BR, et al. Lipopolysaccharide-binding protein (LBP) is associated with total and cardiovascular mortality in individuals with or without stable coronary artery disease-results from the Ludwigshafen Risk and Cardiovascular Health Study (LURIC). Atherosclerosis. (2011) 219:291-7. doi: 10.1016/j.atherosclerosis.2011. 06.001

115. Lepper PM, Schumann C, Triantafilou K, Rasche FM, Schuster T, Frank H, et al. Association of lipopolysaccharide-binding protein and coronary artery disease in men. J Am Coll Cardiol. (2007) 50:2531. doi: $10.1016 /$ j.jacc.2007.02.070
116. Serrano M, Moreno-Navarrete JM, Puig J, Moreno M, Guerra E, Ortega F, et al. Serum lipopolysaccharide-binding protein as a marker of atherosclerosis. Atherosclerosis. (2013) 230:223-7. doi: 10.1016/j.atherosclerosis.2013.07.004

117. Sobczak AIS, Blindauer CA, Stewart AJ. Changes in plasma free fatty acids associated with type-2 diabetes. Nutrients. (2019) 11:2022. doi: 10.3390/nu11092022

118. McNabney SM, Henagan TM. Short chain fatty acids in the colon and peripheral tissues: a focus on butyrate, colon cancer, obesity and insulin resistance. Nutrients. (2017) 9:1348. doi: 10.3390/nu9121348

119. Morrison DJ, Preston T. Formation of short chain fatty acids by the gut microbiota and their impact on human metabolism. Gut Microbes. (2016) 7:189-200. doi: 10.1080/19490976.2015.1134082

120. Koh A, De Vadder F, Kovatcheva-Datchary P, Bäckhed F. From dietary fiber to host physiology: short-chain fatty acids as key bacterial metabolites. Cell. (2016) 165:1332-45. doi: 10.1016/j.cell.2016.05.041

121. Louis P, Flint HJ. Formation of propionate and butyrate by the human colonic microbiota. Environ Microbiol. (2017) 19:29-41. doi: 10.1111/1462-2920.13589

122. Miller TL, Wolin MJ. Pathways of acetate, propionate, and butyrate formation by the human fecal microbial flora. Appl Environ Microbiol. (1996) 62:1589-92. doi: 10.1128/aem.62.5.1589-1592.1996

123. Ghosh S, He W, Gao J, Luo D, Wang J, Chen J, et al. Whole milk consumption is associated with lower risk of coronary artery calcification progression: evidences from the Multi-Ethnic Study of Atherosclerosis. Eur J Nutr. (2020) 60:1049-58. doi: 10.1007/s00394-020-02301-5

124. Aguilar EC, Santos LC, Leonel AJ, de Oliveira JS, Santos EA, Navia-Pelaez $\mathrm{JM}$, et al. Oral butyrate reduces oxidative stress in atherosclerotic lesion sites by a mechanism involving NADPH oxidase down-regulation in endothelial cells. J Nutr Biochem. (2016) 34:99-105. doi: 10.1016/j.jnutbio.2016.05.002

125. Mathew OP, Ranganna K, Milton SG. Involvement of the antioxidant effect and anti-inflammatory response in butyrate-inhibited vascular smooth muscle cell proliferation. Pharmaceuticals. (2014) 7:1008-27. doi: $10.3390 / \mathrm{ph} 7111008$

126. Ranganna K, Yatsu FM, Mathew OP. Emerging epigenetic therapy for vascular proliferative diseases. In: Parthasarathy S, editor. Atherogenesis. Rijeka: InTech (2011). doi: 10.5772/25367

127. Mathew OP, Ranganna K, Yatsu FM. Butyrate, an HDAC inhibitor, stimulates interplay between different posttranslational modifications of histone $\mathrm{H} 3$ and differently alters G1-specific cell cycle proteins in vascular smooth muscle cells. Biomed Pharmacother. (2010) 64:73340. doi: 10.1016/j.biopha.2010.09.017

128. Kasahara K, Krautkramer KA, Org E, Romano KA, Kerby RL, Vivas EI, et al. Interactions between Roseburia intestinalis and diet modulate atherogenesis in a murine model. Nat Microbiol. (2018) 3:1461-71. doi: 10.1038/s41564-018-0272-x

129. Bultman SJ. Bacterial butyrate prevents atherosclerosis. Nat Microbiol. (2018) 3:1332-3. doi: 10.1038/s41564-018-0299-z

130. Bartolomaeus H, Balogh A, Yakoub M, Homann S, Markó L, Höges S, et al. Short-chain fatty acid propionate protects from hypertensive cardiovascular damage. Circulation. (2019) 139:1407-21. doi: 10.1161/CIRCULATIONAHA.118.036652

131. Devlin AS, Marcobal A, Dodd D, Nayfach S, Plummer N, Meyer T, et al. Modulation of a circulating uremic solute via rational genetic manipulation of the gut microbiota. Cell Host Microbe. (2016) 20:70915. doi: 10.1016/j.chom.2016.10.021

132. Gryp T, Huys GRB, Joossens M, Van Biesen W, Glorieux G, Vaneechoutte M. Isolation and quantification of uremic toxin precursor-generating gut bacteria in chronic kidney disease patients. Int J Mol Sci. (2020) 21:1986. doi: 10.3390/ijms 21061986

133. Chao CT, Lin SH. Uremic vascular calcification: the pathogenic roles and gastrointestinal decontamination of uremic toxins. Toxins. (2020) 12:812. doi: $10.3390 /$ toxins 12120812

134. Hénaut L, Mary A, Chillon JM, Kamel S, Massy ZA. The impact of uremic toxins on vascular smooth muscle cell function. Toxins. (2018) 10:218. doi: 10.3390/toxins10060218

135. Kasahara K, Tanoue T, Yamashita T, Yodoi K, Matsumoto T, Emoto T, et al. Commensal bacteria at the crossroad between cholesterol homeostasis 
and chronic inflammation in atherosclerosis. J Lipid Res. (2017) 58:51928. doi: 10.1194/jlr.M072165

136. Aboonabi A, Singh I. Chemopreventive role of anthocyanins in atherosclerosis via activation of Nrf2-ARE as an indicator and modulator of redox. Biomed Pharmacother. (2015) 72:306. doi: 10.1016/j.biopha.2015.03.008

137. Nemet I, Saha PP, Gupta N, Zhu W, Romano KA, Skye SM, et al. A cardiovascular disease-linked gut microbial metabolite acts via adrenergic receptors. Cell. (2020) 180:862-77.e22. doi: 10.1016/j.cell.2020.02.016

138. Zmora N, Suez J, Elinav E. You are what you eat: diet, health and the gut microbiota. Nat Rev Gastroenterol Hepatol. (2019) 16:3556. doi: 10.1038/s41575-018-0061-2

139. Bibbò S, Ianiro G, Giorgio V, Scaldaferri F, Masucci L, Gasbarrini A, et al. The role of diet on gut microbiota composition. Eur Rev Med Pharmacol Sci. (2016) 20:4742-9.

140. De Filippo C, Cavalieri D, Di Paola M, Ramazzotti M, Poullet JB, Massart S, et al. Impact of diet in shaping gut microbiota revealed by a comparative study in children from Europe and rural Africa. Proc Natl Acad Sci USA. (2010) 107:14691-6. doi: 10.1073/pnas.1005963107

141. Kanauchi M, Kanauchi K. The World Health Organization's Healthy Diet Indicator and its associated factors: a cross-sectional study in central Kinki, Japan. Prev Med Rep. (2018) 12:198-202. doi: 10.1016/j.pmedr.2018.09.011

142. Widmer RJ, Flammer AJ, Lerman LO, Lerman A. The Mediterranean diet, its components, and cardiovascular disease. Am J Med. (2015) 128:22938. doi: 10.1016/j.amjmed.2014.10.014

143. Davis C, Bryan J, Hodgson J, Murphy K. Definition of the Mediterranean Diet; a literature review. Nutrients. (2015) 7:9139-53. doi: 10.3390/nu7115459

144. Yannakoulia M, Kontogianni M, Scarmeas N. Cognitive health and Mediterranean diet: just diet or lifestyle pattern? Ageing Res Rev. (2015) 20:74-8. doi: 10.1016/j.arr.2014.10.003

145. Sofi F, Cesari F, Abbate R, Gensini GF, Casini A. Adherence to Mediterranean diet and health status: meta-analysis. BMJ. (2008) 337:a1344. doi: 10.1136/bmj.a1344

146. Childs CE. From the Mediterranean diet to the microbiome. J Nutr. (2018) 148:819-20. doi: 10.1093/jn/nxy087

147. Merra G, Noce A, Marrone G, Cintoni M, Tarsitano MG, Capacci A, et al. Influence of Mediterranean diet on human gut microbiota. Nutrients. (2020) 13:E7. doi: 10.3390/nu13010007

148. Gutiérrez-Díaz I, Fernández-Navarro T, Sánchez B, Margolles A, González S. Mediterranean diet and faecal microbiota: a transversal study. Food Funct. (2016) 7:2347-56. doi: 10.1039/C6FO00105J

149. Vitale M, Giacco R, Laiola M, Della Pepa G, Luongo D, Mangione A, et al. Acute and chronic improvement in postprandial glucose metabolism by a diet resembling the traditional Mediterranean dietary pattern: Can SCFAs play a role? Clin Nutr. (2021) 40:428-37. doi: 10.1016/j.clnu.2020.05.025

150. Nagpal R, Shively CA, Appt SA, Register TC, Michalson KT, Vitolins $\mathrm{MZ}$, et al. Gut microbiome composition in non-human primates consuming a western or mediterranean diet. Front Nutr. (2018) 5:28. doi: 10.3389/fnut.2018.00028

151. De Filippis F, Pellegrini N, Vannini L, Jeffery IB, La Storia A, Laghi L, et al. High-level adherence to a Mediterranean diet beneficially impacts the gut microbiota and associated metabolome. Gut. (2016) 65:181221. doi: 10.1136/gutjnl-2015-309957

152. Torres-Peña JD, Rangel-Zuñiga OA, Alcala-Diaz JF, Lopez-Miranda J, Delgado-Lista J. Mediterranean diet and endothelial function: a review of its effects at different vascular bed levels. Nutrients. (2020) 12:2212. doi: $10.3390 /$ nu12082212

153. Yubero-Serrano EM, Fernandez-Gandara C, Garcia-Rios A, Rangel-Zuñiga OA, Gutierrez-Mariscal FM, Torres-Peña JD, et al. Mediterranean diet and endothelial function in patients with coronary heart disease: an analysis of the CORDIOPREV randomized controlled trial. PLoS Med. (2020) 17:e1003282. doi: 10.1371/journal.pmed.1003282

154. Shannon OM, Mendes I, Köchl C, Mazidi M, Ashor AW, Rubele S, et al. Mediterranean diet increases endothelial function in adults: a systematic review and meta-analysis of randomized controlled trials. J Nutr. (2020) 150:1151-9. doi: 10.1093/jn/nxaa002
155. Casas R, Sacanella E, Urpí-Sardà M, Chiva-Blanch G, Ros E, MartínezGonzález MA, et al. The effects of the mediterranean diet on biomarkers of vascular wall inflammation and plaque vulnerability in subjects with high risk for cardiovascular disease. A randomized trial. PLoS ONE. (2014) 9:e100084. doi: 10.1371/journal.pone.0100084

156. Casas R, Urpi-Sardà M, Sacanella E, Arranz S, Corella D, Castañer O, et al. Anti-inflammatory effects of the mediterranean diet in the early and late stages of atheroma plaque development. Mediators Inflamm. (2017) 2017:3674390. doi: 10.1155/2017/3674390

157. Sala-Vila A, Romero-Mamani ES, Gilabert R, Núñez I, de la Torre $\mathrm{R}$, Corella D, et al. Changes in ultrasound-assessed carotid intimamedia thickness and plaque with a Mediterranean diet: a substudy of the PREDIMED trial. Arterioscler Thromb Vasc Biol. (2014) 34:43945. doi: 10.1161/ATVBAHA.113.302327

158. Gardener H, Wright CB, Cabral D, Scarmeas N, Gu Y, Cheung $\mathrm{K}$, et al. Mediterranean diet and carotid atherosclerosis in the Northern Manhattan Study. Atherosclerosis. (2014) 234:30310. doi: 10.1016/j.atherosclerosis.2014.03.011

159. Olas B. Probiotics, prebiotics and synbiotics-a promising strategy in prevention and treatment of cardiovascular diseases? Int J Mol Sci. (2020) 21:9737. doi: 10.3390/ijms21249737

160. Hume MP, Nicolucci AC, Reimer RA. Prebiotic supplementation improves appetite control in children with overweight and obesity: a randomized controlled trial. Am J Clin Nutr. (2017) 105:790-9. doi: $10.3945 / a j c n .116 .140947$

161. Rivière A, Selak M, Lantin D, Leroy F, De Vuyst L. Bifidobacteria and butyrate-producing colon bacteria: importance and strategies for their stimulation in the human gut. Front Microbiol. (2016) 7:979. doi: $10.3389 /$ fmicb.2016.00979

162. Gibson GR, Probert HM, Loo JV, Rastall RA, Roberfroid MB. Dietary modulation of the human colonic microbiota: updating the concept of prebiotics. Nutr Res Rev. (2004) 17:259-75. doi: 10.1079/NRR200479

163. Fehlbaum S, Prudence K, Kieboom J, Heerikhuisen M, van den Broek T, Schuren FHJ, et al. In vitro fermentation of selected prebiotics and their effects on the composition and activity of the adult gut microbiota. Int $\mathrm{J} \mathrm{Mol}$ Sci. (2018) 19:3097. doi: 10.3390/ijms19103097

164. Nicolucci AC, Hume MP, Martínez I, Mayengbam S, Walter J, Reimer RA. Prebiotics reduce body fat and alter intestinal microbiota in children who are overweight or with obesity. Gastroenterology. (2017) 153:71122. doi: 10.1053 /j.gastro.2017.05.055

165. Beserra BT, Fernandes R, do Rosario VA, Mocellin MC, Kuntz MG, Trindade EB. A systematic review and meta-analysis of the prebiotics and synbiotics effects on glycaemia, insulin concentrations and lipid parameters in adult patients with overweight or obesity. Clin Nutr. (2015) 34:84558. doi: 10.1016/j.clnu.2014.10.004

166. Dongowski G, Jacobasch G, Schmiedl D. Structural stability and prebiotic properties of resistant starch type 3 increase bile acid turnover and lower secondary bile acid formation. J Agric Food Chem. (2005) 53:925767. doi: 10.1021/jf0507792

167. Yang J, Cao RY, Gao R, Mi Q, Dai Q, Zhu F. Physical exercise is a potential "medicine" for atherosclerosis. Adv Exp Med Biol. (2017) 999:26986. doi: 10.1007/978-981-10-4307-9_15

168. Ghaffari S, Roshanravan N. The role of nutraceuticals in prevention and treatment of hypertension: an updated review of the literature. Food Res Int. (2020) 128:108749. doi: 10.1016/j.foodres.2019.108749

169. Frodermann V, Rohde D, Courties G, Severe N, Schloss MJ, Amatullah $\mathrm{H}$, et al. Exercise reduces inflammatory cell production and cardiovascular inflammation via instruction of hematopoietic progenitor cells. Nat Med. (2019) 25:1761-71. doi: 10.1038/s41591-019-0633-x

170. Wewege MA, Thom JM, Rye KA, Parmenter BJ. Aerobic, resistance or combined training: a systematic review and meta-analysis of exercise to reduce cardiovascular risk in adults with metabolic syndrome. Atherosclerosis. (2018) 274:162-71. doi: 10.1016/j.atherosclerosis.2018.05.002

171. Motiani KK, Collado MC, Eskelinen JJ, Virtanen KA, Löyttyniemi E, Salminen $S$, et al. Exercise training modulates gut microbiota profile and improves endotoxemia. Med Sci Sports Exerc. (2020) 52:94104. doi: 10.1249/MSS.0000000000002112 
172. O'Sullivan O, Cronin O, Clarke SF, Murphy EF, Molloy MG, Shanahan F, et al. Exercise and the microbiota. Gut Microbes. (2015) 6:1316. doi: 10.1080/19490976.2015.1011875

173. Monda V, Villano I, Messina A, Valenzano A, Esposito T, Moscatelli F, et al. Exercise modifies the gut microbiota with positive health effects. Oxid Med Cell Longev. (2017) 2017:3831972. doi: 10.1155/2017/3831972

174. Mailing LJ, Allen JM, Buford TW, Fields CJ, Woods JA. Exercise and the gut microbiome: a review of the evidence, potential mechanisms, and implications for human health. Exerc Sport Sci Rev. (2019) 47:7585. doi: 10.1249/JES.0000000000000183

175. Pasini E, Corsetti G, Assanelli D, Testa C, Romano C, Dioguardi FS, et al. Effects of chronic exercise on gut microbiota and intestinal barrier in human with type 2 diabetes. Minerva Med. (2019) 110:311. doi: 10.23736/S0026-4806.18.05589-1

176. Bressa C, Bailén-Andrino M, Pérez-Santiago J, González-Soltero R, Pérez M, Montalvo-Lominchar MG, et al. Differences in gut microbiota profile between women with active lifestyle and sedentary women. PLoS ONE. (2017) 12:e0171352. doi: 10.1371/journal.pone.0171352

177. Meissner M, Havinga R, Boverhof R, Kema I, Groen AK, Kuipers F. Exercise enhances whole-body cholesterol turnover in mice. Med Sci Sports Exerc. (2010) 42:1460-8. doi: 10.1249/MSS.0b013e3181cfcb02

178. Cho KO, Jo YJ, Song BK, Oh JW, Kim YS. Colon transit time according to physical activity and characteristics in South Korean adults. World $J$ Gastroenterol. (2013) 19:550-5. doi: 10.3748/wjg.v19.i4.550

179. Song BK, Cho KO, Jo Y, Oh JW, Kim YS. Colon transit time according to physical activity level in adults. J Neurogastroenterol Motil. (2012) 18:649. doi: 10.5056/jnm.2012.18.1.64

180. Gleeson M, McFarlin B, Flynn M. Exercise and toll-like receptors. Exerc Immunol Rev. (2006) 12:34-53.

181. Simpson RJ, Kunz H, Agha N, Graff R. Exercise and the regulation of immune functions. Prog Mol Biol Transl Sci. (2015) 135:35580. doi: 10.1016/bs.pmbts.2015.08.001

182. Xiao Y, He M, Liang X, She J, He L, Liu Y, et al. Pu-erh tea ameliorates atherosclerosis associated with promoting macrophage apoptosis by reducing NF- $\mathrm{B}$ activation in ApoE knockout mice. Oxid Med Cell Longev. (2018) 2018:3197829. doi: 10.1155/2018/3197829

183. Huang F, Zheng X, Ma X, Jiang R, Zhou W, Zhou S, et al. Theabrownin from $\mathrm{Pu}$-erh tea attenuates hypercholesterolemia via modulation of gut microbiota and bile acid metabolism. Nat Commun. (2019) 10:4971. doi: 10.1038/s41467-019-12896-x

184. Hill C, Guarner F, Reid G, Gibson GR, Merenstein DJ, Pot B, et al. Expert consensus document. The International Scientific Association for probiotics and prebiotics consensus statement on the scope and appropriate use of the term probiotic. Nat Rev Gastroenterol Hepatol. (2014) 11:50614. doi: $10.1038 /$ nrgastro. 2014.66

185. Saavedra JM. Use of probiotics in pediatrics: rationale, mechanisms of action, and practical aspects. Nutr Clin Pract. (2007) 22:351-65. doi: 10.1177/0115426507022003351

186. Yoo JY, Kim SS. Probiotics and prebiotics: present status and future perspectives on metabolic disorders. Nutrients. (2016) 8:173. doi: $10.3390 /$ nu8030173

187. Vasquez EC, Pereira TMC, Peotta VA, Baldo MP, Campos-Toimil M. Probiotics as beneficial dietary supplements to prevent and treat cardiovascular diseases: uncovering their impact on oxidative stress. Oxid Med Cell Longev. (2019) 2019:3086270. doi: 10.1155/2019/3086270

188. Zeng W, Shen J, Bo T, Peng L, Xu H, Nasser MI, et al. Cutting edge:probiotics and fecal microbiota transplantation in immunomodulation. J Immunol Res. (2019) 2019:1603758. doi: 10.1155/2019/1603758

189. Chan YK, El-Nezami H, Chen Y, Kinnunen K, Kirjavainen PV. Probiotic mixture VSL\#3 reduce high fat diet induced vascular inflammation and atherosclerosis in $\mathrm{ApoE}(-/-)$ mice. $A M B$ Express. (2016) 6:61. doi: 10.1186/s13568-016-0229-5

190. Huang Y, Wang J, Quan G, Wang X, Yang L, Zhong L. Lactobacillus acidophilus ATCC 4356 prevents atherosclerosis via inhibition of intestinal cholesterol absorption in apolipoprotein E-knockout mice. Appl Environ Microbiol. (2014) 80:7496-504. doi: 10.1128/AEM.02926-14

191. Tripolt NJ, Leber B, Blattl D, Eder M, Wonisch W, Scharnagl H, et al. Short communication: effect of supplementation with Lactobacillus casei Shirota on insulin sensitivity, $\beta$-cell function, and markers of endothelial function and inflammation in subjects with metabolic syndrome-a pilot study. J Dairy Sci. (2013) 96:89-95. doi: 10.3168/jds.2012-5863

192. Szulińska M, Łoniewski I, Skrypnik K, Sobieska M, Korybalska K, Suliburska J, et al. Multispecies probiotic supplementation favorably affects vascular function and reduces arterial stiffness in obese postmenopausal women-a 12-week placebo-controlled and randomized clinical study. Nutrients. (2018) 10:1672. doi: 10.3390/nu10111672

193. Wu Y, Zhang Q, Ren Y, Ruan Z. Effect of probiotic Lactobacillus on lipid profile: a systematic review and meta-analysis of randomized, controlled trials. PLoS ONE. (2017) 12:e0178868. doi: 10.1371/journal.pone.0178868

194. Yan S, Tian Z, Li M, Li B, Cui W. Effects of probiotic supplementation on the regulation of blood lipid levels in overweight or obese subjects: a meta-analysis. Food Funct. (2019) 10:1747-59. doi: 10.1039/C8FO02163E

195. Deng X, Ma J, Song M, Jin Y, Ji C, Ge W, et al. Effects of products designed to modulate the gut microbiota on hyperlipidaemia. Eur J Nutr. (2019) 58:2713-29. doi: 10.1007/s00394-018-1821-z

196. Ahmadi S, Wang S, Nagpal R,Wang B, Jain S, Razazan A, et al. A human-origin probiotic cocktail ameliorates aging-related leaky gut and inflammation via modulating the microbiota/taurine/tight junction axis. JCI Insight. (2020) 5:e132055. doi: 10.1172/jci.insight.132055

197. Ooijevaar RE, Terveer EM, Verspaget HW, Kuijper EJ, Keller JJ. Clinical application and potential of fecal microbiota transplantation. Annu Rev Med. (2019) 70:335-51. doi: 10.1146/annurev-med-111717-122956

198. Leshem A, Horesh N, Elinav E. Fecal microbial transplantation and its potential application in cardiometabolic syndrome. Front Immunol. (2019) 10:1341. doi: 10.3389/fimmu.2019.01341

199. de Groot PF, Frissen MN, de Clercq NC, Nieuwdorp M. Fecal microbiota transplantation in metabolic syndrome: history, present and future. Gut Microbes. (2017) 8:253-67. doi: 10.1080/19490976.2017.1293224

200. Bárcena C, Valdés-Mas R, Mayoral P, Garabaya C, Durand S, Rodríguez $\mathrm{F}$, et al. Healthspan and lifespan extension by fecal microbiota transplantation into progeroid mice. Nat Med. (2019) 25:1234-42. doi: 10.1038/s41591-019-0504-5

201. Chen R, Xu Y, Wu P, Zhou H, Lasanajak Y, Fang Y, et al. Transplantation of fecal microbiota rich in short chain fatty acids and butyric acid treat cerebral ischemic stroke by regulating gut microbiota. Pharmacol Res. (2019) 148:104403. doi: 10.1016/j.phrs.2019.104403

202. Yu EW, Gao L, Stastka P, Cheney MC, Mahabamunuge J, Torres Soto M, et al. Fecal microbiota transplantation for the improvement of metabolism in obesity: the FMT-TRIM double-blind placebo-controlled pilot trial. PLoS Med. (2020) 17:e1003051. doi: 10.1371/journal.pmed.1003051

203. Hu XF, Zhang WY, Wen Q, Chen WJ, Wang ZM, Chen J, et al. Fecal microbiota transplantation alleviates myocardial damage in myocarditis by restoring the microbiota composition. Pharmacol Res. (2019) 139:41221. doi: 10.1016/j.phrs.2018.11.042

204. Smits LP, Kootte RS, Levin E, Prodan A, Fuentes S, Zoetendal EG,et al. Effect of vegan fecal microbiota transplantation on carnitine- and choline-derived trimethylamine-N-oxide production and vascular inflammation in patients with metabolic syndrome. J Am Heart Assoc. (2018) 7:e008342. doi: 10.1161/JAHA.117.008342

Conflict of Interest: The authors declare that the research was conducted in the absence of any commercial or financial relationships that could be construed as a potential conflict of interest.

Publisher's Note: All claims expressed in this article are solely those of the authors and do not necessarily represent those of their affiliated organizations, or those of the publisher, the editors and the reviewers. Any product that may be evaluated in this article, or claim that may be made by its manufacturer, is not guaranteed or endorsed by the publisher.

Copyright (C) 2021 Shen, Li, Sun, Zang, Zhang, Shao and Wang. This is an openaccess article distributed under the terms of the Creative Commons Attribution License (CC BY). The use, distribution or reproduction in other forums is permitted, provided the original author(s) and the copyright owner(s) are credited and that the original publication in this journal is cited, in accordance with accepted academic practice. No use, distribution or reproduction is permitted which does not comply with these terms. 